\title{
Exact Quantum Dynamics and Tests of the Distorted-wave Approximation for the $\mathrm{O}(3 \mathrm{P})+\mathrm{HD}$ Reaction
}

\author{
Philippe Halvick, Meishan Zhao and Donald G. Truhlar \\ Department of Chemistry, Chemical Physics Program, and Supercomputer Institute, University of \\ Minnesota, Minneapolis, MN 55455-0431, USA
}

David W. Schwenke

NASA Ames Research Center, Mail Stop 230-3, Moffett, CA 94035, USA

Donald J. Kouri

Department of Chemistry and Department of Physics, University of Houston, Houston, TX 77204-5641, USA

\begin{abstract}
We present accurate quantum-dynamical calculations of isotopic branching probabilities in the $\mathrm{O}+\mathrm{HD} \rightarrow \mathrm{OH}+\mathrm{D}$ or $\mathrm{OD}+\mathrm{H}$ reaction on a realistic potential-energy surface. The results are used to test several versions of distorted-wave theory in the threshold region. We find that at low energies and low initial rotational quantum numbers, calculations based on distorted waves that are fully coupled within each arrangement are in excellent agreement with accurate quantal reaction probabilities, but deviations occur for higher energies and higher initial rotational quantum numbers. Uncoupled distorted waves or distorted waves with rotational but not vibrational coupling do not lead to accurate reaction probabilities under any conditions, but the relative product vibrational-rotational distributions are quite accurate not only for the fully coupled distortedwave approximation but also for the rotationally coupled distorted-wave approximation.
\end{abstract}

\section{Introduction}

This special issue of the Faraday Transactions on New Theoretical Methods for Inelastic and Reactive Scattering is indeed timely since there are many research groups working on one or more new such methods at this time. Since this issue features a keynote paper by Connor, we will refer the reader to that paper and our own other recent papers for references to this work, and we will proceed directly to the two methods which form the subject of the present study, the generalized Newton variational principle (GNVP) for reactive scattering calculations with square-integrable $\left(\mathscr{L}^{2}\right)$ expansions of the reactive amplitude density, and the distorted wave Born approximation (DWBA) for reactive scattering with a hierarchy of choices for the distortion potential.

Newton's book ${ }^{1}$ gives an overview of the most popular variational approaches, including the Hulthen-Kohn approach based on differential equations ${ }^{2,3}$ and the Schwinger approach based on integral equations. ${ }^{4}$ In the latter category he also presented a new stationary expression for the $T$ operator which we call the Newton variational principle. Alternative treatments and extensions to multichannel scattering and rearrangements were published by Sloan and Brady, ${ }^{5,6}$ one of the authors and Levin, ${ }^{7,8}$ Rabitz and Conn, ${ }^{9.10}$ and Sloan and Adhikari. ${ }^{11,12}$ The convergence efficiency of the Newton variational principle was studied in detail by Staszewska and one of the present authors. ${ }^{13,14} \mathrm{We}$ and our co-workers have applied a generalization of this method, the GNVP, ${ }^{15,16}$ for several converged calculations of three-dimensional reactive scattering dynamics. ${ }^{15-28}$ Considerable progress on reactive scattering has also been achieved with a method of moments ${ }^{29-36}$ for the amplitude density (MMAD) that results ${ }^{8,16}$ from inserting a finite-basis approximation to the identity to separate the Green's function and the potential in the basic matrix elements of the GNVP. In both the MMAD and the GNVP we have explored various choices for arrangement channel coupling of the reactive amplitude densities, for distortion potentials that define the intra-arrangement coupling, for $\mathscr{L}^{2}$ basis sets, and for the boundary conditions on the distorted wave Green's functions. We have found the Fock scheme $e^{37-41}$ to be more efficient than the Baer-Kouri-Levin-Tobocman scheme, ${ }^{42-44}$ which was employed in earlier ${ }^{45}$ MMAD calculations; we found that rotationally coupled distortion potentials ${ }^{15,16}$ lead to faster convergence of the $\mathscr{L}^{2}$ expansions of the reactive amplitude density than do single-channel distortion potentials $;{ }^{17,18}$ we found a basis $\operatorname{set}^{29,30}$ of products of distributed Gaussians ${ }^{46,47}$ for the radial relative translational coordinate, Percival-Seaton-Arthurs-Dalgarno functions $\mathbf{4 8 , 4 9}^{40}$ coupled orbital-rotational motions and asymptotic vibrational eigenstates ${ }^{30}$ is very efficient; and both real ${ }^{16-19,29,30}$ and complex ${ }^{19,23}$ Green's functions have provided useful accuracy and stability for various problems.

The distorted-wave approximation ${ }^{50,51}$ (DWA) also has an extensive literature. It was originally developed in nuclear physics (where it is often called the distorted-wave Born approximation or DWBA), but subsequently it has also been carefully studied in atomic and chemical physics. There have been many formulations and applications to chemical reactions ${ }^{38,52-110}$ (including collinear, coplanar, 3D, adiabatic, non-adiabatic etc.). The theory is usually considered to be most useful in the threshold region. A critical element in distorted-wave calculations is the choice of distortion potential. Most previous calculations have used uncoupled distorted waves, but, for chemical rearrangements, allowing full coupling within a given arrangement ${ }^{92-95}$ in determining the distorted waves (a procedure introduced earlier in electronatom scattering ${ }^{111}$ and nuclear physics ${ }^{12-115}$ ) leads to significantly more accurate results. In the present article we test both uncoupled and fully coupled (within an arrangement) distorted waves as well as an intermediate choice, allowing for rotational but not vibrational coupling.

Earlier critical tests of the DWA were presented by Schatz, who tested the theory for the $\mathrm{H}+\mathrm{H}_{2},{ }^{106} \mathrm{D}+\mathrm{H}_{2}{ }^{106}$ and $\mathrm{Cl}+\mathrm{HCl}^{116}$ reactions. Schatz also carried out DWA calculations for $\mathrm{O}+\mathrm{H}_{2}, \mathrm{O}+\mathrm{D}_{2}$ and $\mathrm{O}+\mathrm{HD},{ }^{100}$ and we will compare our results to his for $\mathrm{O}+\mathrm{HD}$ as part of the present study. 


\section{Theory}

The GNVP may be applied with either real or complex Green's functions. ${ }^{15,16,19,23}$ We briefly review here the central equations for the former choice. The Hamiltonian in each arrangement $\alpha$ is written as:

$$
H=H_{\alpha}^{\mathrm{D}}+V_{\alpha}^{\mathrm{c}}
$$

where $H_{\alpha}^{\mathrm{D}}$ is a distortion Hamiltonian corresponding to nonreactive scattering, and $V_{\alpha}^{\mathrm{C}}$ is the remaining part of $H$ which goes to zero in each arrangement $\alpha$ for a large separation of the atomic and diatomic fragments. We define $G_{\alpha}^{\mathbf{D}}$ as the principal value Green's function for $H_{\alpha}^{\mathrm{D}}$, given by

$$
G_{\alpha}^{\mathrm{D}}=\left(-\hbar^{2} / 2 \mu\right) \mathscr{P}\left(E-H_{\alpha}^{\mathrm{D}}\right)^{-1}
$$

where $\mu$ is a reduced mass and $E$ is the total energy. We also define a matrix $G^{D}$, diagonal in $\alpha$, containing these Green's functions for various channels, and we define another matrix $U$ which couples the arrangements and provides the residual coupling, if any, within arrangements:

$$
U_{\alpha \alpha^{\prime}}=\left(-2 \mu / \hbar^{2}\right)\left[H-E+\delta_{\alpha \alpha^{\prime}}\left(E-H_{\alpha}^{\mathrm{D}}\right)\right] .
$$

The reactance matrix for the rearrangement problem defined by the full $H$ may be written ${ }^{16}$

$$
\boldsymbol{K}={ }^{0} \boldsymbol{K}+\mathscr{K}
$$

where ${ }^{0} \boldsymbol{K}$ is the reactance matrix corresponding to the distortion problem defined by $H_{\alpha}^{\mathrm{D}}$ and is diagonal in $\alpha$, and $\mathscr{K}$ is the correction due to $U_{\alpha \alpha^{\prime}}$. The GNVP yields

$$
\mathscr{K}=\mathscr{K}^{\mathbf{B}}+\boldsymbol{B}^{\mathrm{T}} \boldsymbol{C}^{-1} \boldsymbol{B}
$$

where $B$ and $C$ are, respectively, the matrix representations of the operators $U G^{\mathrm{D}}$ and $\left(1-G^{\mathrm{D}} U\right) G^{\mathrm{D}}$, and $\mathscr{K}^{\mathrm{B}}$ is the Born term with elements

$$
\mathscr{K}_{n n^{\prime}}^{\mathrm{B}}=\left\langle\psi^{\alpha n} \mid U_{\alpha \alpha^{\prime}} \psi^{\alpha^{\prime} n^{\prime}}\right\rangle
$$

where $\psi^{\alpha n}$ is the regular distorted wave satisfying the equation

$$
\left(H_{\alpha}^{\mathrm{D}}-E\right) \psi^{\alpha n}=0
$$

with real standing-wave boundary conditions. The scattering matrix, from which all state-to-state reaction probabilities can be calculated, is obtained by:

$$
S=(1-\mathrm{i} K)^{-1}(1+\mathrm{i} K) .
$$

The distorted wave approximation to the reactance matrix is given by

$$
\boldsymbol{K}^{\mathrm{DWA}}={ }^{0} \boldsymbol{K}+\mathscr{K}^{\mathbf{B}}
$$

and the DWA to the scattering matrix is given by

$$
S^{\text {DWA }}=\left(1-\mathrm{i} K^{\mathrm{DWA}}\right)^{-1}\left(1+\mathrm{i} K^{\mathrm{DWA}}\right) \text {. }
$$

Since this is obtained with real boundary conditions (RBC) on the solution to eqn (7), it is called DWA-RBC.

The DWA can be formulated in terms of either the real functions $\psi^{\alpha n}$, as in eqn (6), or in terms of the complex incoming and outgoing solutions ${ }^{( \pm)} \psi^{\alpha n}$ of eqn (7). Whereas the boundary conditions used for the solution of eqn (7) are strictly a matter of convenience in the GNVP, and a converged reactance matrix $\boldsymbol{K}$ may be obtained with either choice, the DWA does depend on this choice. With the complex boundary conditions (CBC), the DWA to the scattering matrix is given by

$$
\boldsymbol{S}^{\mathrm{DWA}}={ }^{0} \boldsymbol{S}+\mathscr{S}^{\mathbf{B}}
$$

where ${ }^{0} \boldsymbol{S}$ is the scattering matrix, diagonal in $\alpha$, corresponding to $H_{\alpha}^{\mathrm{D}}$, and $\mathscr{S}^{\mathrm{B}}$ is the Born term:

$$
\mathscr{S}_{n n^{\prime}}^{\mathrm{B}}=\left\langle{ }^{(-)} \psi^{\alpha n}\left|U_{\alpha \alpha^{\prime}}\right|^{(+)} \psi^{\alpha^{\prime} n^{\prime}}\right\rangle
$$

where ${ }^{(-)} \psi^{\alpha n}$ and ${ }^{(+)} \psi^{\alpha^{\prime} n^{\prime}}$ are, respectively, the incoming and outgoing distorted waves satisfying:

$$
\left(H_{\alpha}^{\mathrm{D}}-E\right)^{( \pm)} \psi^{\alpha n}=0 .
$$

The results obtained with eqn (11) are labelled DWA-CBC.

For either the DWA-RBC or DWA-CBC, $H_{\alpha}^{\mathrm{D}}$ may be chosen in various ways. For example, it may include all the coupling within a given arrangement; we call this the fully coupled (FC) distorted-wave approximation (FCDWA). If $H_{\alpha}^{\mathrm{D}}$ couples only the channels in arrangement $\alpha$ that have the same vibrational quantum number $v$, i.e. if it includes only the rotational coupling within individual vibrational manifolds, we call the theory the rotationally coupled distortedwave approximation (RCDWA). Finally, if $H_{\alpha}^{\mathrm{D}}$ corresponds to completely uncoupled channels, we refer to the results as the uncoupled distorted wave approximation (UDWA). The mathematical forms of $H_{\alpha}^{\mathrm{D}}$ for these choices are given elsewhere. ${ }^{16}$ We note for completeness that other choices are also possible, e.g. adiabatic distorted waves or distorted waves based on model potentials, but they will not be considered here. (However, the present accurate quantal benchmark results could be used to test such theories, and we encourage workers developing such methods to use our accurate results to carry out such tests.)

We note that a wide variety of formulations and abbreviations has been employed by other researchers, but we are concerned only with the approximations mentioned above. Thus, e.g. adiabatic uncoupled theories may be more accurate than the UDWA defined above in terms of diabatic channels, but they are not tested here.

\section{Calculations and Results}

Converged quantum-dynamical calculations for the reaction $\mathrm{O}+\mathrm{HD}$ have been presented in two previous papers, and details of the application of the GNVP to this problem are given in those references. ${ }^{23,25}$ In particular, we have used real Green's functions, i.e. GNVP-RGF, for the present converged calculations although in previous work we showed ${ }^{23}$ that the same converged results can be obtained with complex Green's functions for both $\mathrm{O}+\mathrm{H}_{2}$ and $\mathrm{O}+\mathrm{HD}$. All results presented here are for total angular momentum $J$ equal to zero because in a few trial runs we found that the results are not very sensitive to raising $J$, at least for $J=1-3$. Thus we expended our efforts on a thorough set of calculations for a single $J$ rather than on studying the relatively minor dependence on $J$. The calculation of converged quantal cross-sections including all $J$ would require considerably more effort, and the comparisons would be harder to analyse because they involve cancellation of errors for different $J$.

Calculations were performed for the Johnson-WinterSchatz ${ }^{100,117}$ potential-energy surface, which consists of a LEPS function plus a three-centre $\mathrm{HOH}$ barrier term, in the range of total energies, $E$, from 9.2 to $17 \mathrm{kcal} \mathrm{mol}^{-1}$. This energy range includes the threshold regions for both possible chemical products, $\mathrm{OH}$ and $\mathrm{OD}$, for this potential-energy surface. We will compare the above to the coupled states distorted-wave results (denoted CSDWA-CBC) of Schatz and to several sets of our own distorted-wave calculations. In particular, we consider the fully coupled distorted-wave Born approximations with both real and complex boundary conditions (FCDWA-RBC and FCDWA-CBC), the rotationally coupled distorted-wave approximations with both real and 
complex boundary conditions (RCDWA-RBC and RCDWA-CBC), and the uncoupled distorted-wave approximation with real boundary conditions (UDWA-RBC).

We concentrate on reaction probabilities from the initial arrangement $\mathrm{O}+\mathrm{HD}$ to either of the final products summed over the final vibrational and rotational states of that product. We consider only the ground vibrational level $(v=0)$ of HD, but we consider several initial rotational states, with rotational quantum number $j$. In a few cases we also show cumulative reaction probabilities.

The GNVP calculations are well converged. Since convergence was demonstrated previously, ${ }^{25}$ we will not detail it here. The DWA calculations also were well converged. Surprisingly we found this to be rather difficult; in particular, it is harder to converge the FCDWA results with respect to the number of channels than it is to converge the GNVP results. After extensive tests, we developed the parameter sets given in tables $1-3$. Set 1 and set 2 in table 1 have all parameters different with set 2 better converged than set 1 ; for example, the number of channels is increased from 146 in set 1 to 175 in set 2. These two sets of parameters are used to perform the RCDWA-RBC, RCDWA-CBC, and UDWA-RBC calculations. With these parameter sets we achieved very good convergence ( $c a$. three significant figures for most of the probabilities) of the reaction probabilities to produce $\mathrm{OH}$ or OD with respect to all the parameters at all the energies considered here; the convergence checks are given in table 4 . We also used parameter sets 1 and 2 to perform calculations with the FCDWA-RBC and FCDWA-CBC methods. Tables 4 and 5 show that at the lower energies, parameter sets 1 and 2 yield very good (better than $1 \%$ ) convergence for the FCDWA reaction probabilities. However, at energies higher than $14 \mathrm{kcal} \mathrm{mol}^{-1}$, more channels are needed to get converged results. To converge the energies higher than $14 \mathrm{kcal}$ $\mathrm{mol}^{-1}$, we chose parameter sets 3 and 4 for FCDWA-RBC calculations and sets 5 and 6 for FCDWA-CBC calculations. Convergence checks for sets 3-6 are also given in tables 4 and 5. Table 6 shows the convergence of the reaction probabilities

Table 1. Parameter sets 1 and 2 for the tests of the distorted-wave approximation

\begin{tabular}{|c|c|c|c|c|c|c|}
\hline & \multicolumn{3}{|c|}{ set 1} & \multicolumn{3}{|c|}{ set 2} \\
\hline & $\mathrm{O}+\mathrm{HD}$ & $\mathrm{H}+\mathrm{OD}$ & $\mathrm{D}+\mathrm{OH}$ & $\mathrm{O}+\mathrm{HD}$ & $\mathbf{H}+\mathrm{OD}$ & $\mathrm{D}+\mathrm{OH}$ \\
\hline$j_{\max }(v=0)^{a}$ & 9 & 16 & 11 & 10 & 17 & 12 \\
\hline$j_{\max }(v=1)^{a}$ & 8 & 14 & 10 & 9 & 15 & 11 \\
\hline$j_{\max }(v=2)^{a}$ & 7 & 12 & 9 & 8 & 13 & 10 \\
\hline$j_{\max }(v=3)^{a}$ & 6 & 10 & 8 & 7 & 11 & 9 \\
\hline$j_{\max }(v=4)^{a}$ & & 8 & & 4 & 9 & 4 \\
\hline$j_{\max }(v=5)^{a}$ & & 4 & & & 6 & \\
\hline$j_{\max }(v=6)^{a}$ & & & & & 3 & \\
\hline$N_{\mathrm{a}}^{\mathrm{b}}$ & 34 & 70 & 42 & 43 & 81 & 51 \\
\hline$N(\mathrm{HO})^{c}$ & 50 & 50 & 50 & 55 & 55 & 55 \\
\hline$R_{1}\left(\mathrm{a}_{0}\right)^{d}$ & 1.8 & 0.9 & 1.4 & 1.6 & 0.8 & 1.3 \\
\hline$R_{\mathrm{N}(\mathrm{F}), \mathrm{F}}\left(\mathrm{a}_{0}\right)^{d}$ & 15.0 & 12.0 & 13.0 & 15.5 & 12.5 & 13.5 \\
\hline$N_{\alpha \alpha^{\prime}}(\mathrm{QA})^{e}$ & 70 & 70 & 70 & 75 & 75 & 75 \\
\hline$N_{\alpha x}(\mathrm{QA})^{f}$ & 30 & 30 & 30 & 35 & 35 & 35 \\
\hline$N(\mathrm{QV})^{g}$ & 12 & 12 & 12 & 13 & 13 & 13 \\
\hline$N(\mathrm{QGL})^{h}$ & 12 & 12 & 12 & 14 & 14 & 14 \\
\hline$N(\mathrm{QR})^{i}$ & 14 & 14 & 14 & 13 & 13 & 13 \\
\hline
\end{tabular}

${ }^{a}$ Maximum rotational quantum number included in the basis for a given vibrational level. ${ }^{b}$ Number of channels included in the basis for a given arrangement. ' Number of harmonic oscillator functions used to expand the asymptotic vibrational eigenstate. ${ }^{d}$ First and last point in finite difference grid for distorted waves. ${ }^{e}$ Number of points in angular quadrature for integrals coupling different arrangements. ${ }^{s}$ Number of points in angular quadrature for intra-arrangement integrals. ${ }^{g}$ Number of quadrature points for intra-arrangement vibrational integrals. " Number of points in radial Gauss-Legendre quadratures in exchange integrals. ' Number of repetitions of Gauss-Legendre quadratures for radial parts of exchange integrals.

Table 2. Parameters sets 3 and 4 for the tests of the distorted-wave approximation

\begin{tabular}{|c|c|c|c|c|c|c|}
\hline & \multicolumn{3}{|c|}{ set 3} & \multicolumn{3}{|c|}{ set 4} \\
\hline & $\mathrm{O}+\mathrm{HD}$ & $\mathbf{H}+\mathbf{O D}$ & $\mathrm{D}+\mathrm{OH}$ & $\mathrm{O}+\mathrm{HD}$ & $\mathrm{H}+\mathrm{OD}$ & $\mathrm{D}+\mathrm{OH}$ \\
\hline$j_{\max }(v=0)^{a}$ & 15 & 20 & 18 & 16 & 21 & 19 \\
\hline$j_{\max }(v=1)$ & 12 & 16 & 16 & 13 & 17 & 17 \\
\hline$j_{\max }(v=2)$ & 10 & 13 & 14 & 11 & 14 & 15 \\
\hline$j_{\max }(v=3)$ & 9 & 11 & 12 & 10 & 12 & 13 \\
\hline$j_{\max }(v=4)$ & 6 & 9 & 10 & 7 & 10 & 11 \\
\hline$j_{\max }(v=5)$ & 3 & 6 & 4 & 4 & 7 & 5 \\
\hline$j_{\max }(v=6)$ & & 3 & & 2 & 4 & 2 \\
\hline$j_{\max }(v=7)$ & & & & & 1 & \\
\hline$N_{\alpha}$ & 61 & 85 & 80 & 70 & 94 & 89 \\
\hline$N(\mathrm{HO})$ & 50 & 50 & 50 & 55 & 55 & 55 \\
\hline$R_{1, \mathrm{~F}}\left(\mathrm{a}_{0}\right)$ & 1.8 & 0.9 & 1.4 & 1.6 & 0.8 & 1.3 \\
\hline$R_{\mathrm{N}(\mathbf{F}), \mathbf{F}}\left(\mathrm{a}_{0}\right)$ & 15.0 & 12.0 & 13.0 & 15.5 & 12.5 & 13.5 \\
\hline$\left.N_{a \alpha} \cdot \mathbf{Q A}\right)$ & 70 & 70 & 70 & 75 & 75 & 75 \\
\hline$N_{\alpha \alpha}(\mathrm{QA})$ & 30 & 30 & 30 & 35 & 35 & 35 \\
\hline$N(\mathrm{QV})$ & 12 & 12 & 12 & 13 & 13 & 13 \\
\hline$N(\mathrm{QGL})$ & 12 & 12 & 12 & 14 & 14 & 14 \\
\hline$N(\mathrm{QR})$ & 14 & 14 & 14 & 13 & 13 & 13 \\
\hline
\end{tabular}

a See Table 1 for explanations of row labels. 
Table 3. Parameter sets 5 and 6 for the tests of the distorted-wave approximation

\begin{tabular}{|c|c|c|c|c|c|c|}
\hline & \multicolumn{3}{|c|}{ set 5} & \multicolumn{3}{|c|}{ set 6} \\
\hline & $\mathrm{O}+\mathrm{HD}$ & $\mathbf{H}+\mathrm{OD}$ & $\mathrm{D}+\mathrm{OH}$ & $\mathrm{O}+\mathrm{HD}$ & $\mathbf{H}+\mathrm{OD}$ & $\mathrm{D}+\mathrm{OH}$ \\
\hline$j_{\max }(v=0)^{a}$ & 14 & 19 & 17 & 15 & 20 & 18 \\
\hline$j_{\max }(v=1)$ & 11 & 15 & 14 & 12 & 16 & 15 \\
\hline$j_{\max }(v=2)$ & 10 & 12 & 13 & 11 & 13 & 14 \\
\hline$j_{\max }(v=3)$ & 9 & 10 & 12 & 10 & 11 & 13 \\
\hline$j_{\max }(v=4)$ & 8 & 9 & 11 & 9 & 10 & 12 \\
\hline$j_{\max }(v=5)$ & 7 & 8 & 10 & 8 & 9 & 11 \\
\hline$j_{\max }(v=6)$ & & 2 & & 1 & 3 & \\
\hline$j_{\max }(v=7)$ & & & & 1 & & \\
\hline$N_{\alpha}$ & 65 & 82 & 83 & 73 & 91 & 89 \\
\hline$N(\mathrm{HO})$ & 50 & 50 & 50 & 55 & 55 & 55 \\
\hline$R_{1, \mathrm{~F}}\left(\mathrm{a}_{0}\right)$ & 1.8 & 0.9 & 1.4 & 1.6 & 0.8 & 1.3 \\
\hline$R_{\mathrm{N}(\mathrm{F}), \mathrm{F}}\left(\mathrm{a}_{\mathrm{o}}\right)$ & 15.0 & 12.0 & 13.0 & 15.5 & 12.5 & 13.5 \\
\hline$N_{\alpha \alpha^{\prime}}(\mathrm{QA})$ & 70 & 70 & 70 & 75 & 75 & 75 \\
\hline$N_{\alpha a}(\mathrm{QA})$ & 30 & 30 & 30 & 35 & 35 & 35 \\
\hline$N(\mathrm{QV})$ & 12 & 12 & 12 & 13 & 13 & 13 \\
\hline$N(\mathrm{QGL})$ & 12 & 12 & 12 & 14 & 14 & 14 \\
\hline$N(\mathrm{QR})$ & 14 & 14 & 14 & 13 & 13 & 13 \\
\hline
\end{tabular}

${ }^{a}$ See table 1 for explanations of row labels.

with respect to channel basis. In particular, the first three columns of table 6 give the maximum rotational quantum number $j_{\max }(v)$ included in the basis set for each vibrational manifold $v$. Notice especially the high sensitivity of the FCDWA-RBC transition probabilities for $\mathrm{O}+\mathrm{HD}(v=j=0) \rightarrow \mathrm{OH}+\mathrm{D}$ to the channel basis of the initial arrangement $\mathrm{O}+\mathrm{HD}$. The RCDWA and UDWA results are much more stable with respect to increasing the channel basis set (as well as with respect to quadratures), which is reasonable since these methods do not include the full-channel coupling.

Table 7 gives convergence checks for cumulative reaction probabilities (defined as the sum of the state-to-state reaction probabilities over all open initial and final states at a given total energy); table 8 summarizes the number of open channels as a function of energy; tables 9 and 10 list the best converged DWA reaction probabilities for each case and compare them to the GNVP results.

The reaction probabilities in tables $4-7,9$ and 10 are summed over final vibrational quantum number $v^{\prime}$ and final rotational quantum number $j^{\prime}$ (those in table 7 are summed over initial $v$ and $j$ as well). Tables 11-13 show relative finalstate distributions defined by

$$
\rho_{v^{\prime} j^{\prime}}\left(v, j ; \alpha^{\prime}\right)=\frac{P_{\alpha=1, v, j \rightarrow \alpha^{\prime}, v^{\prime} j^{\prime}}}{\sum_{v^{\prime}} \sum_{j^{\prime}} P_{\alpha=1, v, j \rightarrow \alpha^{\prime}, v^{\prime}, j^{\prime}}}
$$

where $\alpha=1$ denotes $\mathrm{O}+\mathrm{HD}, \alpha^{\prime}=2$ denotes $\mathrm{OH}+\mathrm{D}$, $\alpha^{\prime}=3$ denotes $\mathrm{OD}+\mathrm{H}$ and $P_{\alpha, v, j \rightarrow \alpha^{\prime}, v^{\prime}, j^{\prime}}$ is a state-to-state reaction probability for $J=0$.

Table 14 gives average values of the absolute value for the relative errors in these relative probabilities; the precise definition of these average relative errors is more easily stated in an equation:

$$
\% \text { error }=\left\langle\frac{\left|\rho_{v^{\prime} j^{\prime}}(\mathrm{DWA})-\rho_{v^{\prime} j^{\prime}}(\mathrm{GNVP})\right|}{\rho_{v^{\prime} i^{\prime}}(\mathrm{GNVP})}\right\rangle \times 100 \% .
$$

\section{Discussion}

The comparison between our results and the results obtained with the coupled states distorted-wave approximation ${ }^{100}$ (CSDWA) is presented in table 7. [The cumulative reaction probabilities in table 7 are from personal communications from G. C. Schatz. They are a factor of two smaller than the private communication results in ref. (25) because Schatz has now informed us that there was a factor of two error in his computer printout. This error did not affect the results published in ref. (105) and (116).] For $J=0$, the coupledstates approximation is exact; ${ }^{94}$ thus because complex boundary conditions are used in ref. (100), the CSDW results should be identical to the FCDWA CBC ones in table 7 . Instead, however, the table shows that although the FCDWA-CBC calculations are very close $(飞 1 \%)$ to the accurate quantal GNVP results, there are significant differences $(20-36 \%)$ between the CSDWA calculations and the FCDWA results of the present study for the $\mathrm{D}+\mathrm{OH}$ product. To try to understand this, we used a smaller channel basis set comparable to that of ref. (100). This is called parameter set $S$; it has $j_{\max }(v)$ values identical to those in ref. (100) and all other parameters as in set 4. In particular, the $\left\{j_{\max }(v)\right\}$ values are $\{7,5,5,3\}$ for $\mathrm{O}+\mathrm{HD}$ and $\{9,7,7,3$, for the product arrangements. Results for parameter set $S$ are shown in tables 4 and 5 as well as table 7 . Table 7 shows that the results of Schatz do not differ from ours solely due to incompleteness of the channel basis set. This is one reason for carefully documenting the convergence of our own calculations with respect to all numerical parameters, and we again refer the reader to tables 46 for examples of these convergence checks. We particularly note the good stability in table 4 of the $13.8 \mathrm{kcal}^{-1}$ FCDWA-CBC transition probabilities with respect to variations in the channel basis set and all other numerical parameters for six diflerent parameter sets. We conclude that the results presented here are well converged, and the discrepancy between the CSDWA calculations and the present ones is presumed to be due to numerical uncertainties in the calculations of ref. (100).

We next concentrate on table 9, which compares the present DWA calculations by the various schemes to the accurate quantal ones for $j=02$. Consider tirst the FCDWA-CBC method. Table 9 shows very good agreement $\left(\approx 1 \%\right.$ for $\mathrm{O}+\mathrm{HD} \rightarrow \mathrm{OD}+\mathrm{H}$ and $₹ 44^{\prime \prime}$ for $\mathrm{O}+\mathrm{HD} \rightarrow \mathrm{OH}+\mathrm{D})$ of these results with the accurate quantal ones from the lowest energy up to $1+\mathrm{kcal} \mathrm{mol}^{-1}$. For higher energies, the accuracy progressitely deteriorates. becoming $6-9 \%$ at $15 \mathrm{kcal} \mathrm{mol}{ }^{2} .21-27{ }^{\circ}$ "at $16 \mathrm{kcal} \mathrm{mol} i$ and $>400 \%$ at $17 \mathrm{kcal}^{\mathrm{mol}}{ }^{\prime}$ for $\mathrm{O}+\mathrm{HD} \rightarrow \mathrm{OD}+11$ and $2022 \%, 811 \%$ and $c a .300 \%$, respectively, for $\mathrm{O}+\mathrm{HD} \rightarrow \mathrm{OH}+\mathrm{D}$. Because the adiabatic ground-state total energy at the saddle point of the potential surfaee is 16.2 $\mathrm{kcal} \mathrm{mol}{ }^{-1}$ for $\mathrm{O}+\mathrm{HD} \rightarrow \mathrm{OH}+\mathrm{D}$ and $16.3 \mathrm{kcal} \mathrm{mol}^{1}$ for 
Table 4. Convergence of reaction probabilities for $\mathrm{O}+\mathrm{HD}(v=0, j)$ as a function of total energy $E$ (in $\mathrm{kcal} \mathrm{mol}^{-1}$ )

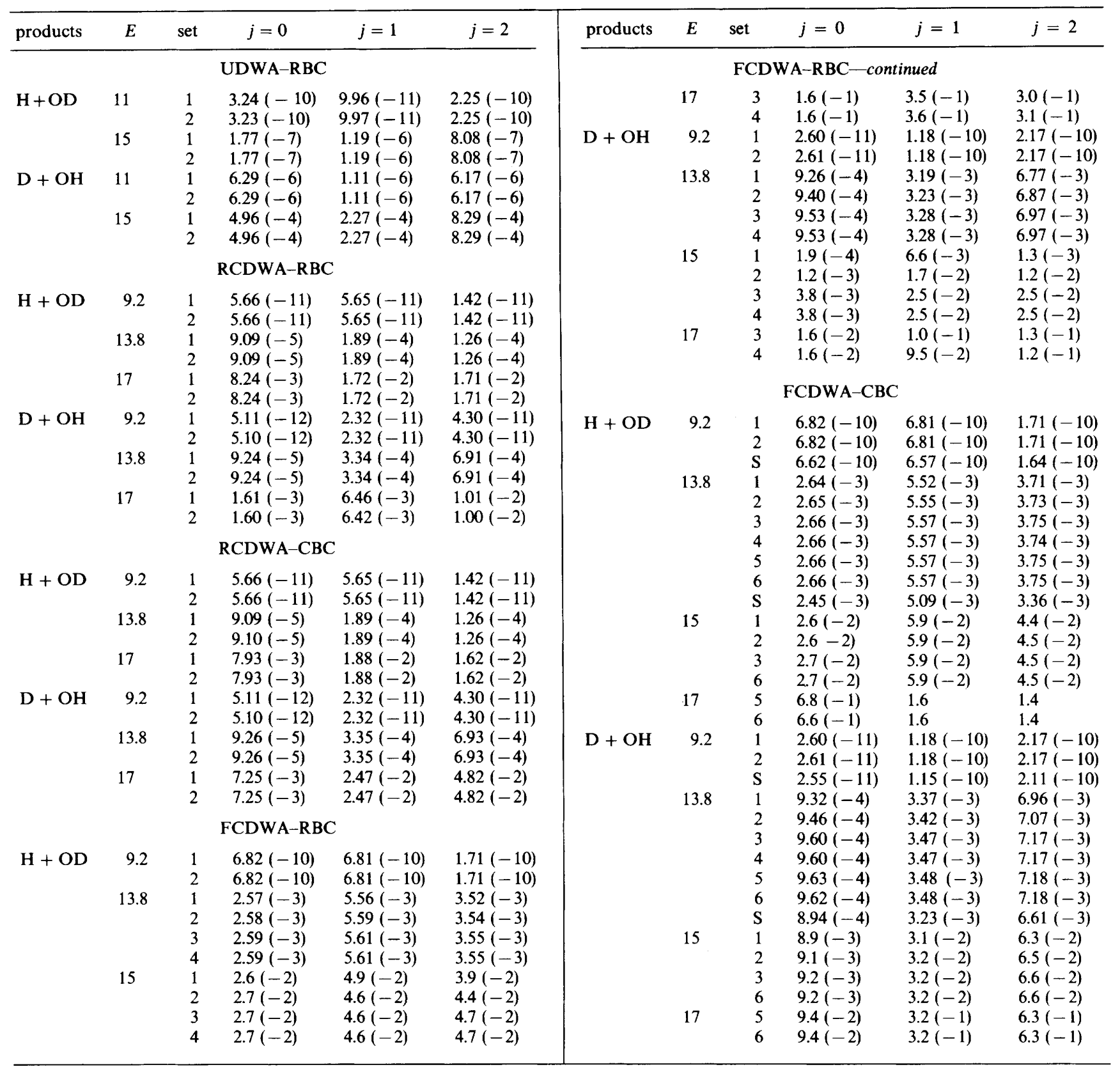

$\mathrm{O}+\mathrm{HD} \rightarrow \mathrm{OD}+\mathrm{H}$, and most of the reaction probabilities are of the order of magnitude of 0.1 at 16 and $17 \mathrm{kcal} \mathrm{mol}^{-1}$, the breakdown of the first-order calculations is not too surprising in a general way, although of course it is useful to document quantitatively its extent.

Next we discuss the DWA-RBC results. The DWA-RBC method has been used previously for inelastic molecular collisions, where the motivation has been that approximations to $\boldsymbol{K}$, as long as they are symmetric, automatically make $\boldsymbol{S}$ unitary. ${ }^{18,119}$ In principle, this may enable DWA methods to remain valid longer as the coupling strength is increased, ${ }^{119}$ and the Heitler relation (8) also includes back-coupling, competition and successive first-order processes within a single collision. ${ }^{120-124}$ To the best of our knowledge the present paper is the first example of applying this approach to reactive scattering, perhaps because of the extra work involved. The extra work is a consequence, first of all, of the fact that to apply the DWA-CBC methods, one needs calculate only the
$S$ matrix elements of interest, but to apply DWA-RBC methods one must calculate the whole reactance matrix to calculate the inverse in eqn (8). We found, in addition, that it is numerically harder to converge the DWA-RBC calculations than the DWA-CBC ones, which may be closely related to the first fact, i.e. one must, in principle, converge all coupled elements of $\boldsymbol{K}$ to obtain a converged value for a single element of $\boldsymbol{S}$.

Table 9 shows that the extra work involved in the RBC calculations does not improve the accuracy at 15-16 kcal $\mathrm{mol}^{-1}$ where the CBC method first becomes significantly inaccurate. Only at $17 \mathrm{kcal} \mathrm{mol}^{-1}$, where the CBC transition probabilities greatly exceed unity, does the RBC method offer any improvement.

The last three columns of table 9 show results obtained by the UDWA and RCDWA approximations. Table 9 shows that neither method is quantitatively accurate at any energy. It is perhaps interesting to notice that the rotationally 
Table 5. Convergence of reaction probabilities for $\mathbf{O}+\operatorname{HD}(v=0$, $j=5$ or 7 ) as a function of total energy $E$ (in kcal mol${ }^{-1}$ )

\begin{tabular}{|c|c|c|c|c|c|}
\hline \multirow[b]{2}{*}{$E$} & \multirow[b]{2}{*}{ set } & \multicolumn{2}{|c|}{$\mathrm{H}+\mathrm{OD}$} & \multicolumn{2}{|c|}{$\mathrm{D}+\mathrm{OH}$} \\
\hline & & $j=5$ & $j=7$ & $j=5$ & $j=7$ \\
\hline \multicolumn{6}{|c|}{ FCDWA-RBC } \\
\hline \multirow[t]{2}{*}{11} & 1 & $1.56(-11)$ & closed & $5.56(-8)$ & closed \\
\hline & 2 & $1.56(-11)$ & closed & $5.56(-8)$ & closed \\
\hline \multirow[t]{2}{*}{11.5} & 1 & $3.04(-10)$ & closed & $9.69(-7)$ & closed \\
\hline & 2 & $3.04(-10)$ & closed & $9.69(-7)$ & closed \\
\hline \multirow[t]{3}{*}{13} & 1 & $4.08(-7)$ & $1.0(-13)$ & $4.10(-4)$ & $1.7(-9)$ \\
\hline & 2 & $4.09(-7)$ & $1.2(-13)$ & $4.13(-4)$ & $1.8(-9)$ \\
\hline & 3 & $4.10(-7)$ & $1.2(-13)$ & $4.17(-4)$ & $1.7(-9)$ \\
\hline \multirow[t]{2}{*}{13.8} & 1 & $7.6(-6)$ & $2.1(-10)$ & $4.0(-3)$ & $1.1(-6)$ \\
\hline & 2 & $7.7(-6)$ & $2.2(-10)$ & $4.0(-3)$ & $1.1(-6)$ \\
\hline \multirow[t]{3}{*}{14} & 1 & $2.7(-5)$ & $2.5(-8)$ & $5.3(-3)$ & $2.6(-6)$ \\
\hline & 2 & $2.9(-5)$ & $2.9(-8)$ & $5.3(-3)$ & $2.9(-6)$ \\
\hline & 3 & $2.9(-5)$ & $2.8(-8)$ & $5.3(-3)$ & $2.9(-6)$ \\
\hline \multirow[t]{3}{*}{15} & 2 & $1.7(-3)$ & $5.4(-6)$ & $1.5(-2)$ & $7.1(-5)$ \\
\hline & 3 & $2.7(-3)$ & $3.3(-9)$ & $4.5(-2)$ & $3.5(-4)$ \\
\hline & 4 & $2.8(-3)$ & $3.4(-9)$ & $4.6(-2)$ & $3.5(-4)$ \\
\hline \multirow[t]{3}{*}{16} & 2 & $2.0(-2)$ & $7.4(-4)$ & $4.2(-3)$ & $2.1(-3)$ \\
\hline & 3 & $8.3(-4)$ & $2.4(-5)$ & $9.6(-3)$ & $5.5(-3)$ \\
\hline & 4 & $8.3(-4)$ & $2.4(-5)$ & $9.6(-3)$ & $5.5(-3)$ \\
\hline \multirow[t]{3}{*}{17} & 1 & $5.4(-3)$ & $5.7(-4)$ & $2.0(-1)$ & $3.3(-2)$ \\
\hline & 3 & $5.3(-3)$ & $3.0(-4)$ & $9.4(-2)$ & $1.3(-2)$ \\
\hline & 4 & $5.3(-3)$ & $2.9(-4)$ & $9.4(-2)$ & $1.3(-2)$ \\
\hline \multicolumn{6}{|c|}{ FCDWA-CBC } \\
\hline \multirow[t]{2}{*}{11} & 1 & $1.56(-11)$ & closed & $5.56(-8)$ & closed \\
\hline & 2 & $1.56(-11)$ & closed & $5.56(-8)$ & closed \\
\hline \multirow[t]{3}{*}{11.5} & 1 & $3.03(-10)$ & closed & $9.69(-7)$ & closed \\
\hline & 2 & $3.05(-10)$ & closed & $9.70(-7)$ & closed \\
\hline & $\mathbf{S}$ & $2.68(-10)$ & closed & $9.41(-7)$ & closed \\
\hline \multirow[t]{2}{*}{13} & 1 & $2.71(-7)$ & $4.8(-15)$ & $4.23(-4)$ & $1.7(-9)$ \\
\hline & 2 & $2.71(-7)$ & $4.9(-15)$ & $4.23(-4)$ & $1.7(-9)$ \\
\hline \multirow[t]{3}{*}{13.8} & 1 & $4.37(-6)$ & $3.2(-13)$ & $4.11(-3)$ & $1.3(-6)$ \\
\hline & 2 & $4.38(-6)$ & $3.4(-13)$ & $4.11(-3)$ & $1.3(-6)$ \\
\hline & S & $3.34(-6)$ & $4.4(-12)$ & $3.63(-3)$ & $8.1(-7)$ \\
\hline \multirow[t]{2}{*}{14} & 1 & $8.2(-6)$ & $2.1(-11)$ & $6.7(-3)$ & $3.6(-6)$ \\
\hline & 2 & $8.3(-6)$ & $2.3(-11)$ & $6.9(-3)$ & $3.7(-6)$ \\
\hline \multirow[t]{3}{*}{15} & 1 & $1.3(-4)$ & $3.5(-9)$ & $5.4(-2)$ & $3.0(-4)$ \\
\hline & 2 & $1.3(-4)$ & $3.6(-9)$ & $5.6(-2)$ & $3.1(-4)$ \\
\hline & 3 & $1.3(-4)$ & $3.7(-9)$ & $5.6(-2)$ & $3.1(-4)$ \\
\hline \multirow[t]{3}{*}{16} & 2 & $9.0(-4)$ & $1.3(-7)$ & $1.8(-1)$ & $4.2(-3)$ \\
\hline & 5 & $1.1(-3)$ & $1.6(-7)$ & $2.1(-1)$ & $4.6(-3)$ \\
\hline & 6 & $1.1(-3)$ & $1.5(-7)$ & $2.1(-1)$ & $4.6(-3)$ \\
\hline \multirow[t]{3}{*}{17} & 1 & $1.8(-3)$ & $1.4(-6)$ & $1.9(-1)$ & $1.3(-2)$ \\
\hline & 5 & $3.6(-3)$ & $2.0(-6)$ & $1.8(-1)$ & $3.2(-2)$ \\
\hline & 6 & $3.6(-3)$ & $2.0(-6)$ & $1.7(-1)$ & $3.2(-2)$ \\
\hline
\end{tabular}

coupled DWA method is typically in error by 'only' 1 or 1.5 orders of magnitude even when the uncoupled version is in error by 3-5 orders of magnitude. We also note that the UDWA results are not monotonically increasing functions of energy. We conclude that intra-arrangement vibrational couplings are too large to be treated by first-order perturbation theory, even when back-coupling and successive firstorder transitions within a single collision are included.

The uncoupled and rotationally coupled DWA transition probabilities are not particularly more accurate for higher initial rotational quantum numbers, and so we present only the fully coupled DWA results for these initial states. The FCDWA results for $j=5$ and 7 are compared to accurate quantal reaction probabilities in table 10 . Here the accuracy is not so good as for $j=0-2$, especially for the $\mathrm{RBC}$ method. It is disappointing that the errors are so large $(30-50 \%)$ even when the accurate transition probabilities are as small as $10^{-3}$.

The simultaneous consideration of tables 11 and 14 along with tables 9 and 10 proves very interesting. Even though the
RCDWA reaction probabilities at $9.2 \mathrm{kcal} \mathrm{mol}^{-1}$ are too small by factors of $5-12$, the relative product distributions are accurate to better than $10 \%$. The relative product distributions for the uncoupled distorted-wave approximation are, however, not very accurate. Tables $12-14$ show that the RCDWA relative product distributions remain much more accurate than the reaction probabilities even as the energy is increased. At $16 \mathrm{kcal} \mathrm{mol}^{-1}$, where even the FCDWA reaction probabilities are becoming inaccurate, the relative product distributions remain accurate to $10 \%$ or better. Since FCDWA calculations are much less demanding than converged quantum dynamics, and RCDWA calculations are much less demanding than FCDWA ones, these comparisons are very encouraging about the use of DWA methods for practical calculations of relative product-state distributions in cases where fully converged quantum dynamics calculations are not available.

Thermal averaging and higher total-angular-momentum contributions are required to compare quantum-mechanical results to experiment or to semiclassical rate constants and are beyond the scope of the present paper. The interested reader is referred to previous papers ${ }^{25,105,125-130}$ for theoretical/experimental and quantal/semiclassical comparisons for the present system.

\section{Conclusions}

We have presented accurate quantum-mechanical reaction probabilities for the reaction of $O$ with $H D$ for a range of energies and initial rotational states, and we have used these results to carry out systematic tests of several versions of the distorted-wave approximations (DWA). The tests of the DWA theories are more reliable than were previously possible because the present quantum results are numerically converged to high precision. We have considered three different kinds of distortion potentials and two kinds of boundary conditions for the distorted waves. We find that at low energies and low initial rotational quantum numbers, calculations based on distorted waves that are fully coupled within each arrangement are in excellent agreement with accurate quantal reaction probabilities, but deviations occur for higher energies and higher initial rotational quantum numbers. Uncoupled distorted waves or distorted waves with rotational but not vibrational coupling do not lead to accurate reaction probabilities under any conditions.

The product vibrational-rotational distributions are quite accurate not only for the fully coupled distorted-wave approximation but also for the rotationally coupled distorted-wave approximation.

Our convergence checks show that distorted-wave calculations in which the distortion potential is fully coupled within each arrangement are very sensitive to the channel basis. Previous fully coupled distorted-wave cumulative reaction probabilities for this system agree with the present ones to within $36 \%$.

The accurate probabilities from GNVP calculations can be used, in future work, to test other approximate methods such as semiclassical tunelling models or distorted-wave approximations with adiabatic distortion potentials.

We are grateful to George Schatz for personal communication of the results in table 7 and for helpful discussions. This work was supported in part by the National Science Foundation, the National Aeronautics and Space Administration, and Minnesota Supercomputer Institute. 
Table 6. Convergence of reaction probabilities with respect to the channel basis set for $\mathrm{O}+\mathrm{HD}(v=0, j) \rightarrow \mathrm{H}+\mathrm{OD}$ or $\mathrm{D}+\mathrm{OH}$ at $E=15 \mathrm{kcal}$ $\mathrm{mol}^{-1 a}$

\begin{tabular}{|c|c|c|c|c|c|}
\hline \multicolumn{3}{|c|}{ channel basis sets } & \multirow[b]{2}{*}{$j$} & \multicolumn{2}{|c|}{ reaction probabilities } \\
\hline HD & OD & $\mathrm{OH}$ & & $\mathbf{H}+\mathbf{O D}$ & $\mathrm{D}+\mathrm{OH}$ \\
\hline & & FCDWA-RBC & & & \\
\hline \multirow[t]{3}{*}{9876} & $\begin{array}{llllll}16 & 14 & 12 & 10 & 8 & 4\end{array}$ & 111098 & 0 & $2.58(-2)$ & $1.93(-4)$ \\
\hline & & & 1 & $4.87(-2)$ & $6.57(-3)$ \\
\hline & & & 2 & $3.94(-2)$ & $1.32(-3)$ \\
\hline \multirow[t]{3}{*}{10987} & $\begin{array}{llllll}16 & 14 & 12 & 10 & 8 & 4\end{array}$ & 111098 & 0 & $2.59(-2)$ & $2.15(-4)$ \\
\hline & & & 1 & $4.85(-2)$ & $7.21(-3)$ \\
\hline & & & 2 & $3.97(-2)$ & $1.73(-3)$ \\
\hline \multirow{3}{*}{10987} & $\begin{array}{llllll}17 & 15 & 13 & 11 & 9 & 6\end{array}$ & 111098 & 0 & $2.59(-2)$ & $1.97(-4)$ \\
\hline & & & 1 & $4.88(-2)$ & $6.59(-3)$ \\
\hline & & & 2 & $3.95(-2)$ & $1.31(-3)$ \\
\hline \multirow[t]{3}{*}{10987} & $\begin{array}{llllll}17 & 15 & 13 & 11 & 9 & 6\end{array}$ & $1211 \quad 109$ & 0 & $2.58(-2)$ & $1.93(-4)$ \\
\hline & & & 1 & $4.87(-2)$ & $6.58(-3)$ \\
\hline & & & 2 & $3.94(-2)$ & $1.33(-3)$ \\
\hline \multirow[t]{3}{*}{98765} & $\begin{array}{llllll}17 & 15 & 13 & 11 & 9 & 6\end{array}$ & $1211 \quad 109$ & 0 & $2.70(-2)$ & $1.32(-3)$ \\
\hline & & & 1 & $4.57(-2)$ & $1.80(-2)$ \\
\hline & & & 2 & $4.48(-2)$ & $1.31(-2)$ \\
\hline \multirow[t]{3}{*}{98765} & $\begin{array}{lllllll}16 & 14 & 12 & 10 & 8 & 6 & 4\end{array}$ & $1211 \quad 109$ & 0 & $2.59(-2)$ & $1.98(-4)$ \\
\hline & & & 1 & $4.89(-2)$ & $6.61(-3)$ \\
\hline & & & 2 & $3.95(-2)$ & $1.31(-3)$ \\
\hline 98765 & $\begin{array}{lllllll}16 & 14 & 12 & 10 & 8 & 6 & 4\end{array}$ & 1110987 & 0 & $2.58(-2)$ & $1.88(-4)$ \\
\hline & & & 1 & $4.89(-2)$ & $6.36(-3)$ \\
\hline & & & 2 & $3.93(-2)$ & $1.29(-3)$ \\
\hline 109876 & $\begin{array}{llllll}16 & 14 & 12 & 10 & 8 & 4\end{array}$ & $11 \quad 1098$ & 0 & $2.72(-2)$ & $1.70(-3)$ \\
\hline & & & 1 & $4.53(-2)$ & $2.04(-2)$ \\
\hline & & & 2 & $4.57(-2)$ & $1.64(-2)$ \\
\hline 1098764 & $\begin{array}{llllll}16 & 14 & 12 & 10 & 8 & 4\end{array}$ & $11 \quad 1098$ & 0 & $2.77(-2)$ & $3.16(-3)$ \\
\hline & & & 1 & $4.55(-2)$ & $2.75(-2)$ \\
\hline & & & 2 & $4.84(-2)$ & $2.82(-2)$ \\
\hline 109876654 & $\begin{array}{llllll}16 & 14 & 12 & 10 & 8 & 4\end{array}$ & 111098 & 0 & $2.84(-2)$ & $4.58(-3)$ \\
\hline & & & 1 & $4.75(-2)$ & $3.22(-2)$ \\
\hline & & & 2 & $5.08(-2)$ & $3.84(-2)$ \\
\hline & & FCDWA-CBC & & & \\
\hline 9876 & $\begin{array}{llllll}16 & 14 & 12 & 10 & 8 & 4\end{array}$ & 111098 & 0 & $2.62(-2)$ & $8.85(-3)$ \\
\hline & & & 1 & $5.87(-2)$ & $3.11(-2)$ \\
\hline & & & 2 & $4.42(-2)$ & $6.29(-2)$ \\
\hline 10987 & $\begin{array}{llllll}16 & 14 & 12 & 10 & 8 & 4\end{array}$ & $11 \quad 1098$ & $\mathbf{0}$ & $2.62(-2)$ & $8.88(-3)$ \\
\hline & & & 1 & $5.87(-2)$ & $3.12(-2)$ \\
\hline & & & 2 & $4.43(-2)$ & $6.32(-2)$ \\
\hline 98765 & $\begin{array}{llllll}16 & 14 & 12 & 10 & 8 & 4\end{array}$ & 111098 & 0 & $2.65(-2)$ & $8.87(-3)$ \\
\hline & & & 1 & $5.93(-2)$ & $3.12(-2)$ \\
\hline & & & 2 & $4.47(-2)$ & $6.31(-2)$ \\
\hline 9876 & $\begin{array}{lllllll}16 & 14 & 12 & 10 & 8 & 6 & 4\end{array}$ & $11 \quad 1098$ & 0 & $2.63(-2)$ & $8.85(-3)$ \\
\hline & & & 1 & $5.90(-2)$ & $3.11(-2)$ \\
\hline & & & 2 & $4.45(-2)$ & $6.29(-2)$ \\
\hline & & RCDWA-RBC & & & \\
\hline 9876 & $\begin{array}{llllll}16 & 14 & 12 & 10 & 8 & 4\end{array}$ & 111098 & 0 & $6.73(-4)$ & $6.81(-4)$ \\
\hline & & & 1 & $1.51(-3)$ & $2.37(-4)$ \\
\hline & & & 2 & $1.11(-3)$ & $4.84(-3)$ \\
\hline 98765 & $\begin{array}{llllll}16 & 14 & 12 & 10 & 8 & 4\end{array}$ & 111098 & 0 & $6.73(-4)$ & $6.81(-4)$ \\
\hline & & & 1 & $1.51(-3)$ & $2.37(-4)$ \\
\hline & & & 2 & $1.11(-3)$ & $4.84(-3)$ \\
\hline 9876 & $\begin{array}{lllllll}16 & 14 & 12 & 10 & 8 & 6 & 4\end{array}$ & $11 \quad 1098$ & 0 & $6.73(-4)$ & $6.81(-4)$ \\
\hline & & & 1 & $1.51(-3)$ & $2.37(-4)$ \\
\hline & & & 2 & $1.11(-3)$ & $4.84(-3)$ \\
\hline 9876 & $\begin{array}{llllll}16 & 14 & 12 & 10 & 8 & 4\end{array}$ & 1110987 & 0 & $6.73(-4)$ & $6.81(-4)$ \\
\hline & & & 1 & $1.51(-3)$ & $2.37(-4)$ \\
\hline & & & 2 & $1.11(-3)$ & $4.84(-3)$ \\
\hline 10987 & $\begin{array}{llllll}16 & 14 & 12 & 10 & 8 & 4\end{array}$ & 111098 & 0 & $6.73(-4)$ & $6.81(-4)$ \\
\hline & & & 1 & $1.51(-3)$ & $2.37(-4)$ \\
\hline & & & 2 & $1.11(-3)$ & $4.84(-3)$ \\
\hline 9876 & 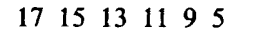 & $11 \quad 1098$ & 0 & $6.73(-4)$ & $6.81(-4)$ \\
\hline & & & 1 & $1.51(-3)$ & $2.37(-4)$ \\
\hline & & & 2 & $1.11(-3)$ & $4.84(-3)$ \\
\hline 9876 & $\begin{array}{llllll}16 & 14 & 12 & 10 & 8 & 4\end{array}$ & $1211 \quad 109$ & 0 & $6.73(-4)$ & $6.81(-4)$ \\
\hline & & & 1 & $1.51(-3)$ & $2.37(-4)$ \\
\hline & & & 2 & $1.11(-3)$ & $4.84(-3)$ \\
\hline
\end{tabular}


Table 6-continued

\begin{tabular}{|c|c|c|c|c|c|}
\hline \multicolumn{3}{|c|}{ channel basis sets } & \multirow[b]{2}{*}{$j$} & \multicolumn{2}{|c|}{ reaction probabilities } \\
\hline HD & OD & $\mathrm{OH}$ & & $\mathbf{H}+\mathrm{OD}$ & $\mathrm{D}+\mathrm{OH}$ \\
\hline \multicolumn{6}{|c|}{ RCDWA-CBC } \\
\hline \multirow[t]{3}{*}{9876} & $\begin{array}{llllll}16 & 14 & 12 & 10 & 8 & 4\end{array}$ & 111098 & 0 & $6.77(-4)$ & $7.08(-4)$ \\
\hline & & & 1 & $1.51(-3)$ & $2.49(-3)$ \\
\hline & & & 2 & $1.13(-3)$ & $5.05(-3)$ \\
\hline \multirow[t]{3}{*}{98765} & $\begin{array}{llllll}16 & 14 & 12 & 10 & 8 & 4\end{array}$ & 111098 & 0 & $6.77(-4)$ & $7.08(-4)$ \\
\hline & & & 1 & $1.51(-3)$ & $2.49(-3)$ \\
\hline & & & 2 & $1.13(-3)$ & $5.05(-3)$ \\
\hline \multirow[t]{3}{*}{9876} & $\begin{array}{llllllll}16 & 14 & 12 & 10 & 8 & 6 & 4\end{array}$ & 111098 & 0 & $6.77(-4)$ & $7.08(-4)$ \\
\hline & & & 1 & $1.51(-3)$ & $2.49(-3)$ \\
\hline & & & 2 & $1.13(-3)$ & $5.05(-3)$ \\
\hline \multirow[t]{3}{*}{9876} & $\begin{array}{llllll}16 & 14 & 12 & 10 & 8 & 4\end{array}$ & 1110987 & 0 & $6.77(-4)$ & $7.08(-4)$ \\
\hline & & & 1 & $1.51(-3)$ & $2.49(-3)$ \\
\hline & & & 2 & $1.13(-3)$ & $5.05(-3)$ \\
\hline \multirow[t]{3}{*}{10987} & $\begin{array}{llllll}16 & 14 & 12 & 10 & 8 & 4\end{array}$ & 111098 & 0 & $6.77(-4)$ & $7.08(-4)$ \\
\hline & & & 1 & $1.51(-3)$ & $2.49(-3)$ \\
\hline & & & 2 & $1.13(-3)$ & $5.05(-3)$ \\
\hline \multirow[t]{3}{*}{9876} & $\begin{array}{llllll}17 & 15 & 13 & 11 & 9 & 5\end{array}$ & $11 \quad 1098$ & 0 & $6.77(-4)$ & $7.08(-4)$ \\
\hline & & & 1 & $1.51(-3)$ & $2.49(-3)$ \\
\hline & & & 2 & $1.13(-3)$ & $5.05(-3)$ \\
\hline \multirow[t]{3}{*}{9876} & $16 \quad 14121084$ & $1211 \quad 109$ & 0 & $6.77(-4)$ & $7.08(-4)$ \\
\hline & & & 1 & $1.51(-3)$ & $2.49(-3)$ \\
\hline & & & 2 & $1.13(-3)$ & $5.05(-3)$ \\
\hline
\end{tabular}

${ }^{a}$ For all calculations in this table, all parameters except the channel basis set are the same as parameter set 1.

Table 7. Cumulative reaction probabilities $(J=0)$ for $\mathrm{O}+\mathrm{HD}$ as functions of total energy $E$ (in kcal mol${ }^{-1}$ )

\begin{tabular}{|c|c|c|c|c|c|c|}
\hline \multirow[b]{2}{*}{ products } & \multirow[b]{2}{*}{$E$} & \multirow[b]{2}{*}{ CSDWA-CBC } & \multicolumn{3}{|c|}{ FCDWA-CBC } & \multirow[b]{2}{*}{ GNVP-RGF } \\
\hline & & & $s$ & set 1 & set 2 & \\
\hline \multirow{3}{*}{$\mathrm{H}+\mathrm{OD}$} & 9.2 & $1.66(-9)$ & $1.49(-9)$ & $1.54(-9)$ & $1.54(-9)$ & $1.54(-9)$ \\
\hline & 11.5 & $2.69(-5)$ & $2.44(-5)$ & $2.44(-5)$ & $2.44(-5)$ & $2.44(-5)$ \\
\hline & 13.8 & $1.35(-2)$ & $1.20(-2)$ & $1.31(-2)$ & $1.31(-2)$ & $1.31(-2)$ \\
\hline \multirow[t]{3}{*}{$\mathrm{D}+\mathrm{OH}$} & 9.2 & $6.7(-10)$ & $4.78(-10)$ & $4.92(-10)$ & $4.93(-10)$ & $4.88(-10)$ \\
\hline & 11.5 & $4.15(-5)$ & $5.25(-5)$ & $5.16(-6)$ & $5.16(-5)$ & $5.15(-5)$ \\
\hline & 13.8 & $2.61(-2)$ & $3.25(-2)$ & $3.49(-2)$ & $3.54(-2)$ & $3.53(-2)$ \\
\hline
\end{tabular}

Table 8. Number of open channels ${ }^{a}$ for parameter set 1 at various total energies $E$ (in $\left.\mathrm{kcal} \mathrm{mol}^{-1}\right)$

\begin{tabular}{|c|c|c|c|c|c|c|c|}
\hline \multirow[b]{2}{*}{$E$} & \multicolumn{2}{|c|}{$\mathrm{O}+\mathrm{HD}$} & \multicolumn{2}{|c|}{$\mathrm{H}+\mathrm{DO}$} & \multicolumn{2}{|c|}{$\mathrm{D}+\mathrm{HO}$} & \multirow[b]{2}{*}{ total } \\
\hline & $v^{\prime}=0$ & $v^{\prime}=1$ & $v^{\prime}=0$ & $v^{\prime}=1$ & $v^{\prime}=0$ & $v^{\prime}=1$ & \\
\hline 9.2 & 6 & 0 & 10 & 0 & 5 & 0 & 21 \\
\hline 11 & 7 & 0 & 12 & 0 & 7 & 0 & 26 \\
\hline 11.5 & 7 & 0 & 13 & 0 & 8 & 0 & 28 \\
\hline 13 & 8 & 0 & 15 & 0 & 10 & 0 & 33 \\
\hline 13.8 & 8 & 0 & 16 & 0 & 10 & 0 & 34 \\
\hline 14 & 8 & 0 & 16 & 0 & 11 & 0 & 35 \\
\hline 15 & 9 & 0 & 17 & 6 & 12 & 0 & 44 \\
\hline 16 & 9 & 2 & 17 & 8 & 12 & 0 & 48 \\
\hline 17 & 10 & 3 & 17 & 10 & 12 & 0 & 52 \\
\hline
\end{tabular}

a The total number of channels included in parameter set 1 is 146 , with 34 for $\mathrm{O}+\mathrm{HD}, \mathbf{4 2}$ for $\mathrm{H}+\mathrm{DO}$ and 70 for $\mathrm{D}+\mathrm{HO}$. 
Table 9. Reaction probabilities for $\mathrm{O}+\mathrm{HD}(v=0, j)$ at various total energies $E$ (in $\mathrm{kcal} \mathrm{mol}^{-1}$ )

\begin{tabular}{|c|c|c|c|c|c|c|c|c|}
\hline products & $E$ & $j$ & GNVP & FCDWA-RBC & FCDWA-CBC & RCDWA-RBC & RCDWA-CBC & UDWA-RBC \\
\hline \multirow[t]{27}{*}{$\mathrm{H}+\mathrm{OD}$} & \multirow[t]{3}{*}{9.2} & 0 & $6.80(-10)$ & $6.82(-10)$ & $6.82(-10)$ & $5.66(-11)$ & $5.66(-11)$ & $2.12(-12)$ \\
\hline & & 1 & $6.80(-10)$ & $6.81(-10)$ & $6.81(-10)$ & $5.65(-11)$ & $5.65(-11)$ & $1.60(-12)$ \\
\hline & & 2 & $1.71(-10)$ & $1.71(-10)$ & $1.71(-10)$ & $1.42(-11)$ & $1.42(-11)$ & $6.76(-13)$ \\
\hline & \multirow[t]{3}{*}{11} & 0 & $1.32(-6)$ & $1.32(-6)$ & $1.32(-6)$ & $8.42(-8)$ & $8.42(-8)$ & $3.24(-10)$ \\
\hline & & 1 & $2.01(-6)$ & $2.01(-6)$ & $2.01(-6)$ & $1.28(-7)$ & $1.28(-7)$ & $9.96(-11)$ \\
\hline & & 2 & $8.68(-7)$ & $8.69(-7)$ & $8.69(-7)$ & $5.51(-8)$ & $5.51(-8)$ & $2.25(-10)$ \\
\hline & \multirow[t]{3}{*}{11.5} & 0 & $6.79(-6)$ & $6.80(-6)$ & $6.80(-6)$ & $3.97(-7)$ & $3.97(-7)$ & $3.79(-10)$ \\
\hline & & 1 & $1.12(-5)$ & $1.12(-5)$ & $1.13(-5)$ & $6.54(-7)$ & $6.54(-7)$ & $7.34(-9)$ \\
\hline & & 2 & $5.39(-6)$ & $5.39(-6)$ & $5.39(-6)$ & $3.12(-7)$ & $3.12(-7)$ & $2.74(-10)$ \\
\hline & \multirow[t]{3}{*}{13} & 0 & $4.27(-4)$ & $4.18(-4)$ & $4.27(-4)$ & $1.80(-5)$ & $1.80(-5)$ & $7.07(-9)$ \\
\hline & & 1 & $8.41(-4)$ & $8.28(-4)$ & $8.39(-4)$ & $3.51(-5)$ & $3.52(-5)$ & $5.33(-8)$ \\
\hline & & 2 & $5.13(-4)$ & $4.97(-4)$ & $5.12(-4)$ & $2.13(-5)$ & $2.12(-5)$ & $1.78(-8)$ \\
\hline & \multirow[t]{3}{*}{13.8} & 0 & $2.64(-3)$ & $2.59(-3)$ & $2.66(-3)$ & $9.09(-5)$ & $9.09(-5)$ & $4.10(-8)$ \\
\hline & & 1 & $5.53(-3)$ & $5.61(-3)$ & $5.57(-3)$ & $1.89(-4)$ & $1.89(-4)$ & $2.50(-7)$ \\
\hline & & 2 & $3.55(-3)$ & $3.75(-3)$ & $3.50(-3)$ & $1.26(-4)$ & $3.71(-3)$ & $3.57(-8)$ \\
\hline & \multirow[t]{3}{*}{14} & 0 & $4.00(-3)$ & $3.95(-3)$ & $4.05(-3)$ & $1.31(-4)$ & $1.31(-4)$ & $1.20(-7)$ \\
\hline & & 1 & $8.50(-3)$ & $8.73(-3)$ & $8.60(-3)$ & $2.77(-4)$ & $2.77(-4)$ & $1.19(-7)$ \\
\hline & & 2 & $5.83(-3)$ & $6.79(-3)$ & $5.90(-3)$ & $1.91(-4)$ & $1.89(-4)$ & $2.36(-10)$ \\
\hline & \multirow[t]{3}{*}{15} & 0 & $2.45(-2)$ & $2.7(-2)$ & $2.6(-2)$ & $6.73(-4)$ & $6.77(-4)$ & $1.77(-7)$ \\
\hline & & 1 & $5.49(-2)$ & $4.6(-2)$ & $5.9(-2)$ & $1.51(-3)$ & $1.51(-3)$ & $1.19(-6)$ \\
\hline & & 2 & $4.14(-2)$ & $4.7(-2)$ & $4.5(-2)$ & $1.12(-3)$ & $1.13(-3)$ & $8.08(-7)$ \\
\hline & \multirow[t]{3}{*}{16} & 0 & $7.88(-2)$ & $3.5(-2)$ & $1.0(-1)$ & $2.39(-3)$ & $2.61(-3)$ & $5.70(-7)$ \\
\hline & & 1 & $1.83(-1)$ & $7.5(-2)$ & $2.3(-1)$ & $6.09(-3)$ & $6.03(-3)$ & $4.50(-6)$ \\
\hline & & 2 & $1.49(-1)$ & $6.1(-2)$ & $1.8(-1)$ & $4.40(-3)$ & $4.87(-3)$ & $1.24(-7)$ \\
\hline & \multirow{3}{*}{17} & 0 & $1.26(-1)$ & $1.6(-1)$ & $6.8(-1)$ & $8.24(-3)$ & $7.93(-3)$ & $2.88(-6)$ \\
\hline & & 1 & $2.95(-1)$ & $3.6(-1)$ & 1.6 & $1.72(-2)$ & $1.88(-2)$ & $1.31(-6)$ \\
\hline & & 2 & $2.55(-1)$ & $3.1(-1)$ & 1.4 & $1.71(-2)$ & $1.62(-2)$ & $8.36(-6)$ \\
\hline \multirow[t]{27}{*}{$\mathrm{D}+\mathrm{OH}$} & \multirow[t]{3}{*}{9.2} & 0 & $2.58(-11)$ & $2.60(-11)$ & $2.60(-11)$ & $5.11(-12)$ & $5.11(-12)$ & $9.75(-9)$ \\
\hline & & 1 & $1.17(-10)$ & $1.18(-10)$ & $1.18(-10)$ & $2.32(-11)$ & $2.32(-11)$ & $4.36(-8)$ \\
\hline & & 2 & $2.15(-10)$ & $2.17(-10)$ & $2.17(-10)$ & $4.30(-11)$ & $4.30(-11)$ & $1.68(-8)$ \\
\hline & \multirow[t]{3}{*}{11} & 0 & $2.71(-7)$ & $2.72(-7)$ & $2.72(-7)$ & $4.39(-8)$ & $4.39(-8)$ & $6.29(-6)$ \\
\hline & & 1 & $1.09(-6)$ & $1.09(-6)$ & $1.09(-6)$ & $1.77(-7)$ & $1.77(-7)$ & $1.11(-6)$ \\
\hline & & 2 & $2.33(-6)$ & $2.33(-6)$ & $2.33(-6)$ & $3.78(-7)$ & $3.78(-7)$ & $6.17(-6)$ \\
\hline & \multirow[t]{3}{*}{11.5} & 0 & $1.71(-6)$ & $1.71(-6)$ & $1.71(-6)$ & $2.57(-7)$ & $2.57(-7)$ & $2.32(-6)$ \\
\hline & & 1 & $6.68(-6)$ & $6.69(-6)$ & $6.70(-6)$ & $1.01(-6)$ & $1.01(-6)$ & $1.15(-5)$ \\
\hline & & 2 & $1.43(-5)$ & $1.43(-5)$ & $1.43(-5)$ & $2.16(-6)$ & $2.16(-6)$ & $7.64(-6)$ \\
\hline & \multirow[t]{3}{*}{13} & 0 & $1.46(-4)$ & $1.38(-4)$ & $1.44(-4)$ & $1.66(-5)$ & $1.68(-5)$ & $8.87(-5)$ \\
\hline & & 1 & $5.38(-4)$ & $5.37(-4)$ & $5.32(-4)$ & $6.19(-5)$ & $6.23(-5)$ & $5.41(-5)$ \\
\hline & & 2 & $1.13(-3)$ & $1.08(-3)$ & $1.12(-3)$ & $1.29(-4)$ & $1.31(-4)$ & $1.74(-4)$ \\
\hline & \multirow[t]{3}{*}{13.8} & 0 & $9.41(-4)$ & $9.53(-4)$ & $9.60(-4)$ & $9.24(-5)$ & $9.26(-5)$ & $3.11(-5)$ \\
\hline & & 1 & $3.40(-3)$ & $3.28(-3)$ & $3.47(-3)$ & $3.34(-4)$ & $3.35(-4)$ & $5.41(-5)$ \\
\hline & & 2 & $7.03(-3)$ & $6.97(-3)$ & $7.17(-3)$ & $6.91(-4)$ & $6.93(-4)$ & $7.25(-5)$ \\
\hline & \multirow[t]{3}{*}{14} & 0 & $1.42(-3)$ & $1.10(-3)$ & $1.47(-3)$ & $1.33(-4)$ & $1.35(-4)$ & $1.31(-4)$ \\
\hline & & 1 & $5.12(-3)$ & $3.87(-3)$ & $5.28(-3)$ & $4.79(-4)$ & $4.86(-4)$ & $8.06(-5)$ \\
\hline & & 2 & $1.05(-2)$ & $8.04(-3)$ & $1.09(-2)$ & $9.88(-4)$ & $1.00(-3)$ & $2.05(-6)$ \\
\hline & 15 & 0 & $7.57(-3)$ & $3.8(-3)$ & $9.2(-3)$ & $6.81(-4)$ & $7.08(-4)$ & $4.96(-4)$ \\
\hline & & 1 & $2.66(-2)$ & $2.5(-2)$ & $3.2(-2)$ & $2.37(-3)$ & $2.49(-3)$ & $2.27(-4)$ \\
\hline & & 2 & $5.39(-2)$ & $2.5(-2)$ & $6.6(-2)$ & $4.84(-3)$ & $5.05(-3)$ & $8.29(-4)$ \\
\hline & 16 & 0 & $1.75(-2)$ & $1.4(-2)$ & $1.6(-2)$ & $2.18(-3)$ & $2.62(-3)$ & $5.69(-4)$ \\
\hline & & 1 & $6.05(-2)$ & $9.4(-3)$ & $5.5(-2)$ & $7.60(-3)$ & $9.04(-3)$ & $4.54(-4)$ \\
\hline & & 2 & $1.20(-1)$ & $6.0(-2)$ & $1.1(-1)$ & $1.55(-2)$ & $1.80(-2)$ & $2.88(-4)$ \\
\hline & 17 & 0 & $2.32(-2)$ & $1.6(-2)$ & $9.4(-2)$ & $1.61(-3)$ & $7.25(-3)$ & $9.52(-4)$ \\
\hline & & 1 & $7.85(-2)$ & $9.5(-2)$ & $3.2(-1)$ & $6.46(-3)$ & $2.47(-2)$ & $9.02(-5)$ \\
\hline & & 2 & $1.51(-1)$ & $1.2(-1)$ & $6.3(-1)$ & $1.01(-2)$ & $4.82(-2)$ & $1.14(-3)$ \\
\hline
\end{tabular}


Table 10. Reaction probabilities for $\mathrm{O}+\mathrm{HD}(v=0, j)$ as functions of total energy $E$ (in $\mathrm{kcal} \mathrm{mol}^{-1}$ )

\begin{tabular}{llllll}
\hline products & $E$ & $j$ & GNVP & FCDWA-RBC & FCDWA-CBC \\
\hline H+ OD & 11 & 5 & $1.55(-11)$ & $1.56(-11)$ & $1.56(-11)$ \\
& 11.5 & 5 & $3.02(-10)$ & $3.04(-10)$ & $3.05(-10)$ \\
& 13 & 5 & $2.71(-7)$ & $4.1(-7)$ & $2.71(-7)$ \\
& 13.8 & 5 & $4.37(-6)$ & $7.7(-6)$ & $4.38(-6)$ \\
& 14 & 5 & $8.17(-6)$ & $2.9(-5)$ & $8.3(-6)$ \\
& 15 & 5 & $1.23(-4)$ & $2.8(-3)$ & $1.3(-4)$ \\
& 16 & 5 & $8.33(-4)$ & $8.3(-4)$ & $1.1(-3)$ \\
& 17 & 7 & $1.20(-7)$ & $2.4(-5)$ & $1.5(-7)$ \\
& 5 & $2.86(-3)$ & $5.3(-3)$ & $3.6(-3)$ \\
& & 7 & $1.78(-6)$ & $2.9(-4)$ & $2.0(-6)$ \\
& 11 & 5 & $5.50(-8)$ & $5.56(-8)$ & $5.56(-8)$ \\
& 11.5 & 5 & $9.64(-7)$ & $9.69(-7)$ & $9.70(-7)$ \\
& 13 & 5 & $4.26(-4)$ & $4.1(-4)$ & $4.23(-4)$ \\
& 13.8 & 5 & $4.14(-3)$ & $4.0(-3)$ & $4.11(-3)$ \\
& 14 & 5 & $6.74(-3)$ & $5.3(-3)$ & $6.9(-3)$ \\
& 15 & 5 & $4.63(-2)$ & $4.6(-2)$ & $5.6(-2)$ \\
& 16 & 5 & $1.22(-1)$ & $9.6(-3)$ & $2.1(-1)$ \\
& & 7 & $2.99(-3)$ & $5.5(-3)$ & $4.6(-3)$ \\
& 17 & 5 & $1.71(-1)$ & $9.4(-2)$ & $1.7(-1)$ \\
& & 7 & $1.46(-2)$ & $1.3(-2)$ & $3.2(-2)$ \\
\hline
\end{tabular}

Table 11. Comparison of accurate quantum mechanics to the distorted-wave approximation for state-to-state reaction probabilities greater than $1.0 \times 10^{-6}$ of $\mathrm{O}+\mathrm{HD}(v=0, j)$ at an energy of $9.2 \mathrm{kcal} \mathrm{mol}^{-1}$

\begin{tabular}{|c|c|c|c|c|c|c|c|}
\hline products & $j$ & $v^{\prime}$ & $j^{\prime}$ & GNVP & FCDWA-CBC & RCDWA-CBC & UDWA-RBC \\
\hline \multirow[t]{9}{*}{$\mathbf{H}+\mathbf{O D}$} & 0 & 0 & 0 & $5.80(-2)$ & $5.80(-2)$ & $5.81(-2)$ & $6.81(-2)$ \\
\hline & & & 1 & $1.60(-1)$ & $1.60(-1)$ & $1.60(-1)$ & $1.75(-1)$ \\
\hline & & & 2 & $2.22(-1)$ & $2.22(-1)$ & $2.22(-1)$ & $2.39(-1)$ \\
\hline & & & 3 & $2.28(-1)$ & $2.28(-1)$ & $2.28(-1)$ & $1.22(-1)$ \\
\hline & & & 4 & $1.81(-1)$ & $1.80(-1)$ & $1.80(-1)$ & $3.17(-1)$ \\
\hline & & & 5 & $1.05(-1)$ & $1.05(-1)$ & $1.05(-1)$ & $1.42(-2)$ \\
\hline & & & 6 & $3.97(-2)$ & $3.97(-2)$ & $3.99(-2)$ & $6.19(-2)$ \\
\hline & & & 7 & $6.85(-3)$ & $6.86(-3)$ & $6.91(-3)$ & $3.46(-3)$ \\
\hline & & & 8 & $1.50(-4)$ & $1.51(-4)$ & $1.53(-4)$ & $4.43(-5)$ \\
\hline \multirow[t]{5}{*}{$\mathrm{D}+\mathrm{OH}$} & 0 & 0 & 0 & $4.69(-2)$ & $4.65(-2)$ & $4.58(-2)$ & $2.61(-3)$ \\
\hline & & & 1 & $2.06(-1)$ & $2.05(-1)$ & $2.04(-1)$ & $6.32(-1)$ \\
\hline & & & 2 & $4.42(-1)$ & $4.42(-1)$ & $4.41(-1)$ & $2.83(-1)$ \\
\hline & & & 3 & $3.05(-1)$ & $3.05(-1)$ & $3.09(-1)$ & $8.29(-2)$ \\
\hline & & & 4 & $6.12(-4)$ & $6.07(-4)$ & $6.01(-4)$ & $2.97(-4)$ \\
\hline \multirow[t]{9}{*}{$\mathbf{H}+\mathrm{OD}$} & 2 & 0 & 0 & $5.47(-2)$ & $5.49(-2)$ & $5.42(-2)$ & $5.58(-2)$ \\
\hline & & & 1 & $1.52(-1)$ & $1.53(-1)$ & $1.54(-1)$ & $1.45(-1)$ \\
\hline & & & 2 & $2.15(-1)$ & $2.15(-1)$ & $2.13(-1)$ & $2.09(-1)$ \\
\hline & & & 3 & $2.26(-1)$ & $2.26(-1)$ & $2.25(-1)$ & $1.19(-1)$ \\
\hline & & & 4 & $1.85(-1)$ & $1.85(-1)$ & $1.85(-1)$ & $3.71(-1)$ \\
\hline & & & 5 & $1.13(-1)$ & $1.13(-1)$ & $1.13(-1)$ & $1.76(-2)$ \\
\hline & & & 6 & $4.49(-2)$ & $4.50(-2)$ & $4.57(-2)$ & $7.77(-2)$ \\
\hline & & & 7 & $8.25(-3)$ & $8.30(-3)$ & $8.52(-3)$ & $4.97(-3)$ \\
\hline & & & 8 & $1.95(-4)$ & $1.95(-4)$ & $2.03(-4)$ & $5.04(-5)$ \\
\hline \multirow{5}{*}{$\mathrm{D}+\mathrm{OH}$} & 2 & 0 & 0 & $5.63(-2)$ & $5.60(-2)$ & $5.56(-2)$ & $2.77(-3)$ \\
\hline & & & 1 & $2.24(-1)$ & $2.24(-1)$ & $2.23(-1)$ & $6.67(-1)$ \\
\hline & & & 2 & $4.38(-1)$ & $4.38(-1)$ & $4.37(-1)$ & $2.53(-1)$ \\
\hline & & & 3 & $2.28(-1)$ & $2.83(-1)$ & $2.84(-1)$ & $7.86(-2)$ \\
\hline & & & 4 & $5.53(-4)$ & $5.51(-4)$ & $5.37(-4)$ & $3.19(-4)$ \\
\hline \multirow{9}{*}{$\mathbf{H}+\mathrm{OD}$} & 5 & 0 & 0 & $5.42(-2)$ & $5.33(-2)$ & $5.27(-2)$ & $5.73(-2)$ \\
\hline & & & 1 & $1.51(-1)$ & $1.49(-1)$ & $1.47(-1)$ & $1.47(-1)$ \\
\hline & & & 2 & $2.13(-1)$ & $2.11(-1)$ & $2.10(-1)$ & $2.09(-1)$ \\
\hline & & & 3 & $2.25(-1)$ & $2.25(-1)$ & $2.25(-1)$ & $1.18(-1)$ \\
\hline & & & 4 & $1.86(-1)$ & $1.87(-1)$ & $1.89(-1)$ & $3.69(-1)$ \\
\hline & & & 5 & $1.15(-1)$ & $1.17(-1)$ & $1.19(-1)$ & $1.74(-2)$ \\
\hline & & & 6 & $4.68(-2)$ & $4.80(-2)$ & $4.95(-2)$ & $7.66(-2)$ \\
\hline & & & 7 & $8.94(-3)$ & $9.21(-3)$ & $9.65(-3)$ & $5.06(-3)$ \\
\hline & & & 8 & $2.21(-4)$ & $2.27(-4)$ & $2.43(-4)$ & $5.11(-5)$ \\
\hline \multirow[t]{5}{*}{$\mathrm{D}+\mathrm{OH}$} & 5 & 0 & 0 & $5.92(-2)$ & $5.92(-2)$ & $4.58(-2)$ & $2.61(-3)$ \\
\hline & & & 1 & $2.25(-1)$ & $2.15(-1)$ & $2.04(-1)$ & $6.32(-1)$ \\
\hline & & & 2 & $4.22(-1)$ & $4.24(-1)$ & $4.42(-1)$ & $2.83(-1)$ \\
\hline & & & 3 & $2.93(-1)$ & $3.05(-1)$ & $3.09(-1)$ & $8.29(-2)$ \\
\hline & & & 4 & $6.31(-4)$ & $6.31(-4)$ & $6.01(-4)$ & $2.97(-4)$ \\
\hline
\end{tabular}


Table 12. Comparison of accurate quantum mechanics to the distorted-wave approximation for state-to-state reaction probabilities greater than $1.0 \times 10^{-6}$ of $\mathrm{O}+\mathrm{HD}(v=0, j)$ at an energy of $13.8 \mathrm{kcal} \mathrm{mol}^{-1}$

\begin{tabular}{|c|c|c|c|c|c|c|c|}
\hline products & $j$ & $v^{\prime}$ & $j^{\prime}$ & GNVP & FCDWA-CBC & RCDWA-CBC & UDWA-RBC \\
\hline \multirow[t]{14}{*}{$\mathrm{H}+\mathrm{OD}$} & 0 & 0 & 0 & $3.11(-2)$ & $3.09(-2)$ & $3.20(-2)$ & $1.01(-2)$ \\
\hline & & & 1 & $8.90(-2)$ & $8.83(-2)$ & $9.12(-2)$ & $1.32(-1)$ \\
\hline & & & 2 & $1.34(-1)$ & $1.33(-1)$ & $1.38(-1)$ & $4.27(-2)$ \\
\hline & & & 3 & $1.60(-1)$ & $1.59(-1)$ & $1.63(-1)$ & $2.31(-1)$ \\
\hline & & & 4 & $1.64(-1)$ & $1.63(-1)$ & $1.65(-1)$ & $4.20(-2)$ \\
\hline & & & 5 & $1.48(-1)$ & $1.47(-1)$ & $1.47(-1)$ & $2.88(-1)$ \\
\hline & & & 6 & $1.16(-1)$ & $1.15(-1)$ & $1.14(-1)$ & $2.44(-2)$ \\
\hline & & & 7 & $7.94(-2)$ & $7.86(-2)$ & $7.69(-2)$ & $1.74(-1)$ \\
\hline & & & 8 & $4.58(-2)$ & $4.55(-2)$ & $4.35(-2)$ & $2.44(-3)$ \\
\hline & & & 9 & $2.15(-2)$ & $2.13(-2)$ & $1.99(-2)$ & $4.87(-2)$ \\
\hline & & & 10 & $7.73(-3)$ & $7.67(-3)$ & $6.97(-3)$ & $6.56(-4)$ \\
\hline & & & 11 & $1.91(-3)$ & $1.90(-3)$ & $1.67(-3)$ & $4.05(-3)$ \\
\hline & & & 12 & $2.61(-4)$ & $2.60(-4)$ & $2.19(-4)$ & $5.66(-5)$ \\
\hline & & & 13 & $1.12(-5)$ & $1.12(-5)$ & $8.92(-6)$ & $2.59(-5)$ \\
\hline \multirow[t]{10}{*}{$\mathrm{D}+\mathrm{OH}$} & 0 & 0 & 0 & $1.63(-2)$ & $1.62(-2)$ & $1.51(-2)$ & $2.01(-1)$ \\
\hline & & & 1 & $5.28(-2)$ & $5.26(-2)$ & $4.99(-2)$ & $2.91(-2)$ \\
\hline & & & 2 & $9.97(-2)$ & $9.94(-2)$ & $9.51(-2)$ & $3.23(-2)$ \\
\hline & & & 3 & $1.55(-1)$ & $1.55(-1)$ & $1.50(-1)$ & $8.23(-2)$ \\
\hline & & & 4 & $2.03(-1)$ & $2.03(-1)$ & $2.02(-1)$ & $1.43(-1)$ \\
\hline & & & 5 & $2.11(-1)$ & $2.11(-1)$ & $2.14(-1)$ & $6.56(-2)$ \\
\hline & & & 6 & $1.64(-1)$ & $1.64(-1)$ & $1.69(-1)$ & $2.62(-1)$ \\
\hline & & & 7 & $8.06(-2)$ & $8.10(-2)$ & $8.58(-2)$ & $1.70(-1)$ \\
\hline & & & 8 & $1.69(-2)$ & $1.73(-2)$ & $1.87(-2)$ & $6.42(-3)$ \\
\hline & & & 9 & $2.25(-4)$ & $2.27(-4)$ & $2.49(-4)$ & $8.71(-3)$ \\
\hline \multirow[t]{14}{*}{$\mathbf{H}+\mathbf{O D}$} & 2 & 0 & 0 & $2.76(-2)$ & $2.75(-2)$ & $2.67(-2)$ & $8.15(-3)$ \\
\hline & & & 1 & $7.96(-2)$ & $7.92(-2)$ & $7.71(-2)$ & $1.01(-1)$ \\
\hline & & & 2 & $1.22(-1)$ & $1.22(-1)$ & $1.19(-1)$ & $3.53(-2)$ \\
\hline & & & 3 & $1.50(-1)$ & $1.49(-1)$ & $1.47(-1)$ & $2.11(-1)$ \\
\hline & & & 4 & $1.60(-1)$ & $1.59(-1)$ & $1.57(-1)$ & $4.15(-2)$ \\
\hline & & & 5 & $1.50(-1)$ & $1.50(-1)$ & $1.49(-1)$ & $3.05(-1)$ \\
\hline & & & 6 & $1.25(-1)$ & $1.25(-1)$ & $1.26(-1)$ & $2.76(-2)$ \\
\hline & & & 7 & $9.08(-2)$ & $9.03(-2)$ & $9.29(-2)$ & $2.10(-1)$ \\
\hline & & & 8 & $5.63(-2)$ & $5.60(-2)$ & $5.84(-2)$ & $3.00(-3)$ \\
\hline & & & 9 & $2.88(-2)$ & $2.86(-2)$ & $3.03(-2)$ & $5.32(-2)$ \\
\hline & & & 10 & $1.13(-2)$ & $1.12(-2)$ & $1.21(-2)$ & $5.69(-4)$ \\
\hline & & & 11 & $3.07(-3)$ & $3.08(-3)$ & $3.42(-3)$ & $2.83(-3)$ \\
\hline & & & 12 & $4.74(-4)$ & $4.75(-4)$ & $5.40(-4)$ & $6.19(-5)$ \\
\hline & & & 13 & $2.31(-5)$ & $2.31(-5)$ & $2.72(-5)$ & $4.31(-5)$ \\
\hline \multirow[t]{10}{*}{$\mathrm{D}+\mathrm{OH}$} & 2 & 0 & 0 & $1.69(-2)$ & $1.68(-2)$ & $1.63(-2)$ & $2.99(-1)$ \\
\hline & & & 1 & $5.48(-2)$ & $5.45(-2)$ & $5.30(-2)$ & $5.68(-2)$ \\
\hline & & & 2 & $1.02(-1)$ & $1.02(-1)$ & $9.99(-2)$ & $8.62(-2)$ \\
\hline & & & 3 & $1.58(-1)$ & $1.57(-1)$ & $1.55(-1)$ & $7.88(-2)$ \\
\hline & & & 4 & $2.03(-1)$ & $2.03(-1)$ & $2.03(-1)$ & $1.37(-1)$ \\
\hline & & & 5 & $2.09(-1)$ & $2.10(-1)$ & $2.11(-1)$ & $6.34(-2)$ \\
\hline & & & 6 & $1.61(-1)$ & $1.61(-1)$ & $1.64(-1)$ & $2.10(-1)$ \\
\hline & & & 7 & $7.89(-2)$ & $7.93(-2)$ & $8.16(-2)$ & $6.59(-2)$ \\
\hline & & & 8 & $1.69(-2)$ & $1.72(-2)$ & $1.79(-2)$ & $1.72(-3)$ \\
\hline & & & 9 & $2.36(-4)$ & $2.36(-4)$ & $2.46(-4)$ & $2.17(-3)$ \\
\hline \multirow[t]{14}{*}{$\mathbf{H}+\mathbf{O D}$} & 5 & 0 & 0 & $2.03(-2)$ & $2.02(-2)$ & $1.64(-2)$ & $9.38(-3)$ \\
\hline & & & 1 & $5.95(-2)$ & $5.94(-2)$ & $4.88(-2)$ & $1.23(-1)$ \\
\hline & & & 2 & $9.42(-2)$ & $9.45(-2)$ & $7.96(-2)$ & $4.18(-2)$ \\
\hline & & & 3 & $1.24(-1)$ & $1.23(-1)$ & $1.08(-1)$ & $2.38(-1)$ \\
\hline & & & 4 & $1.42(-1)$ & $1.41(-1)$ & $1.30(-1)$ & $4.38(-2)$ \\
\hline & & & 5 & $1.46(-1)$ & $1.45(-1)$ & $1.42(-1)$ & $3.03(-1)$ \\
\hline & & & 6 & $1.36(-1)$ & $1.35(-1)$ & $1.41(-1)$ & $2.58(-2)$ \\
\hline & & & 7 & $1.13(-1)$ & $1.13(-1)$ & $1.26(-1)$ & $1.81(-1)$ \\
\hline & & & 8 & $8.15(-2)$ & $8.15(-2)$ & $9.80(-2)$ & $2.26(-3)$ \\
\hline & & & 9 & $4.92(-2)$ & $4.91(-2)$ & $6.39(-2)$ & $3.05(-2)$ \\
\hline & & & 10 & $2.33(-2)$ & $2.35(-2)$ & $3.31(-2)$ & $3.88(-4)$ \\
\hline & & & 11 & $7.96(-3)$ & $7.95(-3)$ & $1.22(-2)$ & $2.14(-3)$ \\
\hline & & & 12 & $1.55(-3)$ & $1.55(-3)$ & $2.63(-3)$ & $4.69(-6)$ \\
\hline & & & 13 & $9.68(-3)$ & $9.68(-3)$ & $1.82(-4)$ & $4.16(-5)$ \\
\hline \multirow[t]{10}{*}{$\mathrm{D}+\mathrm{OH}$} & 5 & 0 & 0 & $1.59(-2)$ & $1.60(-2)$ & $1.64(-2)$ & $1.11(-1)$ \\
\hline & & & 1 & $5.10(-2)$ & $5.13(-2)$ & $5.23(-2)$ & $1.49(-2)$ \\
\hline & & & 2 & $9.42(-2)$ & $9.44(-2)$ & $9.61(-2)$ & $1.21(-2)$ \\
\hline & & & 3 & $1.44(-1)$ & $1.45(-1)$ & $1.46(-1)$ & $1.65(-2)$ \\
\hline & & & 4 & $1.89(-1)$ & $1.89(-1)$ & $1.88(-1)$ & $8.26(-2)$ \\
\hline & & & 5 & $2.05(-1)$ & $2.05(-1)$ & $2.02(-1)$ & $5.14(-2)$ \\
\hline & & & 6 & $1.73(-1)$ & $1.73(-1)$ & $1.71(-1)$ & $3.19(-1)$ \\
\hline & & & 7 & $9.98(-2)$ & $9.93(-2)$ & $9.93(-2)$ & $3.52(-1)$ \\
\hline & & & 8 & $2.80(-2)$ & $2.82(-2)$ & $2.89(-2)$ & $1.85(-2)$ \\
\hline & & & 9 & $5.43(-4)$ & $5.38(-4)$ & $5.80(-4)$ & $2.18(-2)$ \\
\hline
\end{tabular}


Table 13. Comparison of accurate quantum mechanics to the distorted-wave approximation for state-to-state reaction probabilities greater than $1.0 \times 10^{-6}$ of $\mathrm{O}+\mathrm{HD}(v=0, j)$ at an energy of $16 \mathrm{kcal} \mathrm{mol}^{-1}$

\begin{tabular}{|c|c|c|c|c|c|c|c|}
\hline products & $j$ & $v^{\prime}$ & $j^{\prime}$ & GNVP & FCDWA-CBC & RCDWA-CBC & UDWA-RBC \\
\hline \multirow[t]{23}{*}{$\mathbf{H}+\mathbf{O D}$} & 0 & 0 & 0 & $2.67(-2)$ & $2.62(-2)$ & $2.96(-2)$ & $2.01(-2)$ \\
\hline & & & 1 & $7.68(-2)$ & $7.52(-2)$ & $8.45(-2)$ & $1.03(-1)$ \\
\hline & & & 2 & $1.17(-1)$ & $1.15(-1)$ & $1.28(-1)$ & $1.36(-5)$ \\
\hline & & & 3 & $1.43(-1)$ & $1.41(-1)$ & $1.53(-1)$ & $3.35(-1)$ \\
\hline & & & 4 & $1.51(-1)$ & $1.50(-1)$ & $1.58(-1)$ & $7.07(-3)$ \\
\hline & & & 5 & $1.43(-1)$ & $1.43(-1)$ & $1.45(-1)$ & $2.56(-1)$ \\
\hline & & & 6 & $1.22(-1)$ & $1.23(-1)$ & $1.18(-1)$ & $1.48(-2)$ \\
\hline & & & 7 & $9.26(-2)$ & $9.43(-2)$ & $8.47(-2)$ & $7.41(-2)$ \\
\hline & & & 8 & $6.24(-2)$ & $6.42(-2)$ & $5.31(-2)$ & $2.04(-2)$ \\
\hline & & & 9 & $3.66(-2)$ & $3.81(-2)$ & $2.87(-2)$ & $3.09(-2)$ \\
\hline & & & 10 & $1.82(-2)$ & $1.91(-2)$ & $1.28(-2)$ & $1.08(-2)$ \\
\hline & & & 11 & $7.38(-3)$ & $7.83(-3)$ & $4.56(-3)$ & $1.20(-3)$ \\
\hline & & & 12 & $2.28(-3)$ & $2.44(-3)$ & $1.21(-3)$ & $2.56(-3)$ \\
\hline & & & 13 & $4.86(-4)$ & $5.28(-4)$ & $2.10(-4)$ & $5.65(-4)$ \\
\hline & & & 14 & $5.65(-5)$ & $6.19(-5)$ & $1.92(-5)$ & $6.53(-5)$ \\
\hline & & & 15 & $2.09(-6)$ & $2.33(-6)$ & $5.21(-7)$ & $5.70(-6)$ \\
\hline & & 1 & 0 & $3.35(-5)$ & $3.38(-5)$ & $3.60(-5)$ & $2.93(-3)$ \\
\hline & & & 1 & $8.85(-5)$ & $8.96(-5)$ & $1.80(-4)$ & $4.42(-2)$ \\
\hline & & & 2 & $1.12(-4)$ & $1.14(-4)$ & $1.61(-4)$ & $1.48(-2)$ \\
\hline & & & 3 & $9.95(-5)$ & $1.03(-4)$ & $6.36(-5)$ & $4.96(-2)$ \\
\hline & & & 4 & $6.20(-5)$ & $6.52(-5)$ & $1.15(-4)$ & $1.16(-3)$ \\
\hline & & & 5 & $2.39(-5)$ & $2.57(-5)$ & $1.23(-5)$ & $9.28(-3)$ \\
\hline & & & 6 & $3.88(-6)$ & $4.29(-6)$ & $3.22(-6)$ & $1.35(-3)$ \\
\hline \multirow{11}{*}{$\mathrm{D}+\mathrm{OH}$} & 0 & 0 & 0 & $1.89(-2)$ & $1.83(-2)$ & $1.54(-2)$ & $4.69(-2)$ \\
\hline & & & 1 & $5.91(-2)$ & $5.72(-2)$ & $4.86(-2)$ & $1.46(-3)$ \\
\hline & & & 2 & $1.04(-1)$ & $1.01(-1)$ & $8.76(-2)$ & $6.84(-2)$ \\
\hline & & & 3 & $1.51(-1)$ & $1.47(-1)$ & $1.32(-1)$ & $1.00(-1)$ \\
\hline & & & 4 & $1.86(-1)$ & $1.82(-1)$ & $1.72(-1)$ & $6.82(-2)$ \\
\hline & & & 5 & $1.91(-1)$ & $1.89(-1)$ & $1.90(-1)$ & $2.19(-1)$ \\
\hline & & & 6 & $1.55(-1)$ & $1.58(-1)$ & $1.71(-1)$ & $2.60(-1)$ \\
\hline & & & 7 & $9.20(-2)$ & $9.77(-2)$ & $1.16(-1)$ & $1.70(-1)$ \\
\hline & & & 8 & $3.61(-2)$ & $4.03(-2)$ & $5.39(-2)$ & $4.80(-2)$ \\
\hline & & & 9 & $6.70(-3)$ & $8.98(-3)$ & $1.44(-2)$ & $1.53(-2)$ \\
\hline & & & 10 & $2.70(-4)$ & $3.36(-4)$ & $1.04(-4)$ & $2.11(-3)$ \\
\hline \multirow[t]{23}{*}{$\mathbf{H}+\mathbf{O D}$} & 2 & 0 & 0 & $2.36(-2)$ & $2.39(-2)$ & $2.21(-2)$ & $9.76(-3)$ \\
\hline & & & 1 & $6.83(-2)$ & $6.91(-2)$ & $6.44(-2)$ & $4.50(-2)$ \\
\hline & & & 2 & $1.06(-1)$ & $1.07(-1)$ & $1.01(-1)$ & $7.31(-6)$ \\
\hline & & & 3 & $1.33(-1)$ & $1.34(-1)$ & $1.27(-1)$ & $2.18(-1)$ \\
\hline & & & 4 & $1.45(-1)$ & $1.46(-1)$ & $1.43(-1)$ & $5.16(-3)$ \\
\hline & & & 5 & $1.43(-1)$ & $1.43(-1)$ & $1.42(-1)$ & $2.40(-1)$ \\
\hline & & & 6 & $1.27(-1)$ & $1.27(-1)$ & $1.28(-1)$ & $1.86(-2)$ \\
\hline & & & 7 & $1.01(-1)$ & $1.01(-1)$ & $1.05(-1)$ & $1.24(-1)$ \\
\hline & & & 8 & $7.15(-2)$ & $7.09(-2)$ & $7.67(-2)$ & $3.87(-2)$ \\
\hline & & & 9 & $4.42(-2)$ & $4.38(-2)$ & $4.89(-2)$ & $6.52(-2)$ \\
\hline & & & 10 & $2.32(-2)$ & $2.29(-2)$ & $2.64(-2)$ & $3.98(-2)$ \\
\hline & & & 11 & $9.95(-3)$ & $9.78(-3)$ & $1.17(-2)$ & $1.15(-2)$ \\
\hline & & & 12 & $3.26(-3)$ & $3.20(-3)$ & $3.96(-3)$ & $9.96(-3)$ \\
\hline & & & 13 & $7.37(-4)$ & $7.24(-4)$ & $9.22(-4)$ & $1.37(-3)$ \\
\hline & & & 14 & $9.07(-5)$ & $8.98(-5)$ & $1.18(-4)$ & $6.62(-4)$ \\
\hline & & & 15 & $3.52(-6)$ & $3.55(-6)$ & $4.76(-6)$ & $1.56(-5)$ \\
\hline & & 1 & 0 & $2.94(-5)$ & $2.98(-5)$ & $3.38(-5)$ & $2.88(-3)$ \\
\hline & & & 1 & $8.02(-5)$ & $8.11(-5)$ & $2.03(-4)$ & $4.97(-2)$ \\
\hline & & & 2 & $1.08(-4)$ & $1.09(-4)$ & $1.64(-4)$ & $1.94(-2)$ \\
\hline & & & 3 & $1.04(-4)$ & $1.05(-4)$ & $7.63(-5)$ & $8.04(-2)$ \\
\hline & & & 4 & $7.16(-5)$ & $7.24(-5)$ & $1.42(-4)$ & $2.10(-3)$ \\
\hline & & & 5 & $3.09(-5)$ & $3.12(-5)$ & $4.37(-6)$ & $1.76(-2)$ \\
\hline & & & 6 & $5.68(-6)$ & $5.71(-6)$ & $6.26(-6)$ & $2.77(-3)$ \\
\hline \multirow[t]{11}{*}{$\mathrm{D}+\mathrm{OH}$} & 2 & 0 & 0 & $1.85(-2)$ & $1.79(-2)$ & $1.58(-2)$ & $1.43(-1)$ \\
\hline & & & 1 & $5.77(-2)$ & $5.58(-2)$ & $4.97(-2)$ & $1.29(-2)$ \\
\hline & & & 2 & $1.02(-1)$ & $9.86(-2)$ & $8.91(-2)$ & $1.27(-1)$ \\
\hline & & & 3 & $1.47(-1)$ & $1.44(-1)$ & $1.36(-1)$ & $1.34(-1)$ \\
\hline & & & 4 & $1.82(-1)$ & $1.79(-1)$ & $1.71(-1)$ & $7.81(-2)$ \\
\hline & & & 5 & $1.88(-1)$ & $1.87(-1)$ & $1.87(-1)$ & $1.85(-1)$ \\
\hline & & & 6 & $1.57(-1)$ & $1.59(-1)$ & $1.67(-1)$ & $1.71(-1)$ \\
\hline & & & 7 & $9.75(-2)$ & $1.02(-1)$ & $1.14(-1)$ & $1.09(-1)$ \\
\hline & & & 8 & $4.05(-2)$ & $4.51(-2)$ & $5.44(-2)$ & $3.24(-2)$ \\
\hline & & & 9 & $9.00(-3)$ & $1.12(-2)$ & $1.50(-2)$ & $4.79(-3)$ \\
\hline & & & 10 & $5.02(-4)$ & $7.79(-4)$ & $1.18(-3)$ & $2.51(-3)$ \\
\hline \multirow{5}{*}{$\mathbf{H}+\mathbf{O D}$} & 5 & 0 & 0 & $2.01(-2)$ & $2.09(-2)$ & $1.74(-2)$ & $9.70(-3)$ \\
\hline & & & 1 & $5.83(-2)$ & $6.05(-2)$ & $5.07(-2)$ & $4.03(-2)$ \\
\hline & & & 2 & $9.09(-2)$ & $9.36(-2)$ & $7.95(-2)$ & $6.29(-6)$ \\
\hline & & & 3 & $1.15(-1)$ & $1.18(-1)$ & $1.01(-1)$ & $1.94(-1)$ \\
\hline & & & 4 & $1.29(-1)$ & $1.30(-1)$ & $1.15(-1)$ & $4.58(-3)$ \\
\hline
\end{tabular}


Table 13-continued

\begin{tabular}{|c|c|c|c|c|c|c|c|}
\hline products & $j$ & $v^{\prime}$ & $j^{\prime}$ & GNVP & FCDWA-CBC & RCDWA-CBC & UDWA-RBC \\
\hline & & & 5 & $1.30(-1)$ & $1.30(-1)$ & $1.21(-1)$ & $1.98(-1)$ \\
\hline & & & 6 & $1.22(-1)$ & $1.20(-1)$ & $1.18(-1)$ & $1.38(-2)$ \\
\hline & & & 7 & $1.06(-1)$ & $1.02(-1)$ & $1.09(-1)$ & $1.10(-1)$ \\
\hline & & & 8 & $8.57(-2)$ & $7.76(-2)$ & $9.53(-2)$ & $4.71(-2)$ \\
\hline & & & 9 & $6.30(-2)$ & $6.47(-2)$ & $7.70(-2)$ & $8.63(-2)$ \\
\hline & & & 10 & $4.16(-2)$ & $4.53(-2)$ & $5.60(-2)$ & $4.90(-2)$ \\
\hline & & & 11 & $2.42(-2)$ & $2.50(-2)$ & $3.47(-2)$ & $1.89(-2)$ \\
\hline & & & 12 & $1.03(-2)$ & $9.25(-3)$ & $1.70(-2)$ & $3.32(-2)$ \\
\hline & & & 13 & $3.24(-3)$ & $3.54(-3)$ & $5.90(-3)$ & $4.36(-3)$ \\
\hline & & & 14 & $5.76(-4)$ & $5.41(-4)$ & $1.15(-3)$ & $2.01(-3)$ \\
\hline & & & 15 & $3.14(-5)$ & $2.98(-5)$ & $7.19(-5)$ & $1.46(-5)$ \\
\hline & & 1 & 0 & $1.43(-5)$ & $1.52(-5)$ & $2.73(-5)$ & $2.63(-3)$ \\
\hline & & & 1 & $4.32(-5)$ & $4.53(-5)$ & $1.09(-4)$ & $5.12(-2)$ \\
\hline & & & 2 & $7.07(-5)$ & $7.14(-5)$ & $8.92(-5)$ & $2.09(-2)$ \\
\hline & & & 3 & $8.70(-5)$ & $8.42(-5)$ & $5.19(-5)$ & $9.09(-2)$ \\
\hline & & & 4 & $7.91(-5)$ & $7.35(-5)$ & $1.49(-4)$ & $2.45(-3)$ \\
\hline & & & 5 & $4.63(-5)$ & $4.13(-5)$ & $1.48(-5)$ & $2.02(-2)$ \\
\hline & & & 6 & $1.17(-5)$ & $1.01(-5)$ & $1.89(-5)$ & $2.73(-3)$ \\
\hline \multirow[t]{12}{*}{$\mathrm{D}+\mathbf{O H}$} & 5 & 0 & 0 & $1.25(-2)$ & $1.27(-2)$ & $1.37(-2)$ & $5.24(-2)$ \\
\hline & & & 1 & $3.94(-2)$ & $4.00(-2)$ & $4.27(-2)$ & $2.60(-3)$ \\
\hline & & & 2 & $7.14(-2)$ & $7.25(-2)$ & $7.59(-2)$ & $3.53(-2)$ \\
\hline & & & 3 & $1.09(-1)$ & $1.10(-1)$ & $1.13(-1)$ & $8.28(-2)$ \\
\hline & & & 4 & $1.49(-1)$ & $1.48(-1)$ & $1.48(-1)$ & $6.14(-2)$ \\
\hline & & & 5 & $1.80(-1)$ & $1.80(-1)$ & $1.70(-1)$ & $2.01(-1)$ \\
\hline & & & 6 & $1.85(-1)$ & $1.82(-1)$ & $1.70(-1)$ & $2.74(-1)$ \\
\hline & & & 7 & $1.14(-1)$ & $1.24(-1)$ & $1.40(-1)$ & $2.05(-1)$ \\
\hline & & & 8 & $9.73(-2)$ & $9.65(-2)$ & $8.73(-2)$ & $6.17(-2)$ \\
\hline & & & 9 & $3.74(-2)$ & $3.41(-2)$ & $3.37(-2)$ & $2.51(-2)$ \\
\hline & & & 10 & $4.58(-3)$ & $4.49(-3)$ & $4.39(-3)$ & $2.83(-3)$ \\
\hline & & & 11 & $1.29(-5)$ & $1.30(-5)$ & $1.34(-5)$ & $2.90(-5)$ \\
\hline
\end{tabular}

Table 14. The average percentage absolute relative error of the distorted-wave approximation for relative reaction probabilities greater than $1.0 \times 10^{-6}$ as compared to the accurate quantum-mechanical results for the reaction $\mathrm{O}+\mathrm{HD}(v=0, j)$ at total energy $E$ (in $\mathrm{kcal}^{\mathrm{mol}}{ }^{-1}$ )

\begin{tabular}{|c|c|c|c|c|c|}
\hline$E$ & products & $j$ & FCDWA-CBC & RCDWA-CBC & UDWA-RBC \\
\hline \multirow[t]{6}{*}{9.2} & $\mathbf{H}+\mathrm{OD}$ & 0 & 0.15 & 0.46 & 46 \\
\hline & & 2 & 0.21 & 1.4 & 48 \\
\hline & & 5 & 1.6 & 4.0 & 47 \\
\hline & $\mathrm{D}+\mathrm{OH}$ & 0 & 0.43 & 1.3 & 92 \\
\hline & & 2 & 0.25 & 1.1 & 90 \\
\hline & & 5 & 1.8 & 9.4 & 87 \\
\hline \multirow[t]{6}{*}{13.8} & $\mathbf{H}+\mathbf{O D}$ & 0 & 0.66 & 6.3 & 88 \\
\hline & & 2 & 0.38 & 5.4 & 75 \\
\hline & & 5 & 0.36 & 29 & 81 \\
\hline & $\mathrm{D}+\mathrm{OH}$ & 0 & 0.50 & 5.3 & 540 \\
\hline & & 2 & 0.45 & 2.7 & 280 \\
\hline & & 5 & 0.43 & 2.3 & 526 \\
\hline \multirow[t]{6}{*}{16} & $\mathbf{H}+\mathbf{O D}$ & 0 & 4.2 & 32 & 8590 \\
\hline & & 2 & 0.96 & 27 & 12000 \\
\hline & & 5 & 5.3 & 47 & 14800 \\
\hline & $\mathrm{D}+\mathrm{OH}$ & 0 & 8.5 & 30 & 126 \\
\hline & & 2 & 10 & 29 & 121 \\
\hline & & 5 & 2.4 & 8.0 & 77 \\
\hline
\end{tabular}

\section{References}

1 R. G. Newton, Scattering Theory of Waves and Particles (McGraw-Hill, New York, 1966), chap. 11.

2 L. Hulthén, Kgl. Fysiograf. Sallskap. Lund. Forh., 1944, 14, 257.

3 W. Kohn, Phys. Rev., 1948, 74, 1763.

4 B. A. Lippmann and J. Schwinger, Phys. Rev., 1950, 79, 469.

5 I. H. Sloan and T. J. Brady, Phys. Rev. C, 1972, 6, 701.

6 I. H. Sloan and T. J. Brady, Phys. Rev. C, 1974, 9, 4.

7 D. J. Kouri, J. Chem. Phys., 1973, 58, 1914.

8 D. J. Kouri and F. S. Levin, Phys. Rev. C, 1975, 11, 352.

9 H. Rabitz and R. Conn, Phys. Rev. A, 1973, 7, 577.

10 R. Conn and H. Rabitz, J. Chem. Phys., 1974, 61, 600.

11 I. H. Sloan and S. K. Adhikari, Nucl. Phys., 1974, A235, 352.
12 S. K. Adhikari and I. H. Sloan, Nucl. Phys., 1975, A241, 429; A254, 545 (E)

13 G. Staszewska and D. G. Truhlar, Chem. Phys. Lett., 1986, 130, 341.

14 G. Staszewska and D. G. Truhlar, J. Chem. Phys., 1987, 86, 2793.

15 D. W. Schwenke, K. Haug, D. G. Truhlar, Y. Sun, J. Z. H. Zhang and D. J. Kouri, J. Phys. Chem., 1987, 91, 6080.

16 D. W. Schwenke, K. Haug, M. Zhao, D. G. Truhlar, Y. Sun, J. Z. H. Zhang and D. J. Kouri, J. Phys. Chem., 1988, 92, 3202.

17 M. Mladenovic, M. Zhao, D. G. Truhlar, D. W. Schwenke, Y. Sun and D. J. Kouri, Chem. Phys. Lett., 1988, 146, 358. 
18 M. Zhao, M. Mladenovic, D. G. Truhlar, D. W. Schwenke, Y. Sun, D. J. Kouri and N. C. Blais, J. Am. Chem. Soc., 1989, 111, 852.

19 D. W. Schwenke, M. Mladenovic, M. Zhao, D. G. Truhlar, Y. Sun and D. J. Kouri, in Supercomputer Algorithms for Reactivity, Dynamics, and Kinetics of Small Molecules, ed. A. Laganà (Kluwer, Dordrecht, 1989), p. 131.

20 M. Mladenovic, M. Zhao, D. G. Truhlar, D. W. Schwenke, Y. Sun and D. J. Kouri, J. Phys. Chem., 1988, 92, 7035.

21 C-h. Yu, Y. Sun, D. J. Kouri, P. Halvick, D. G. Truhlar and D. W. Schwenke, J. Chem. Phys., 1989, 90, 7608.

22 M. Zhao, D. G. Truhlar, D. J. Kouri, Y. Sun and D. W. Schwenke, Chem. Phys. Lett., 1989, 156, 281.

23 Y. Sun, C-h. Yu, D. J. Kouri, D. W. Schwenke, P. Halvick, M. Mladenovic and D. G. Truhlar, J. Chem. Phys., 1989, 91, 1643.

24 N. C. Blais, M. Zhao, M. Mladenovic, D. G. Truhlar, D. W. Schwenke, Y. Sun and D. J. Kouri, J. Chem. Phys., 1989, 91, 1038.

25 G. C. Lynch, P. Halvick, D. G. Truhlar, B. C. Garrett, D. W. Schwenke and D. J. Kouri, Z. Naturforsch., Teil A, 1989, 44, 427.

26 C-h. Yu, D. J. Kouri, M. Zhao, D. G. Truhlar and D. W. Schwenke, Chem. Phys. Lett., 1989, 157, 491.

27 M. Zhao, M. Mladenovic, D. G. Truhlar, D. W. Schwenke, O. Sharafeddin, Y. Sun and D. J. Kouri, J. Chem. Phys., in press.

28 C-h. Yu, D. J. Kouri, M. Zhao, D. G. Truhlar and D. W. Schwenke, Int. J. Quantum Chem. Symp., 1989, 23, 45

29 K. Haug, D. W. Schwenke, Y. Shima, D. G. Truhlar, J. Zhang and D. J. Kouri, J. Phys. Chem., 1986, 90, 6757.

30 J. Z. H. Zhang, D. J. Kouri, K. Haug, D. W. Schwenke, Y. Shima and D. G. Truhlar, J. Chem. Phys., 1988, 88, 2492.

31 K. Haug, D. W. Schwenke, D. G. Truhlar, Y. Zhang, J. Z. H. Zhang and D. J. Kouri, J. Chem. Phys., 1987, 87, 1892.

32 K. Haug, D. W. Schwenke, Y. Shima, D. G. Truhlar, J. Z. H. Zhang, Y. Zhang, Y. Sun, D. J. Kouri and B. C. Garrett, in Science and Engineering on Cray Supercomputers (Cray Research, Minneapolis, 1987), p. 427.

33 J. Z. H. Zhang, Y. Zhang, D. J. Kouri, B. C. Garrett, K. Haug, D. W. Schwenke and D. G. Truhlar, Faraday Discuss. Chem. Soc., 1987, 84, 371

34 D. W. Schwenke, K. Haug, D. G. Truhlar, R. H. Schweitzer, J. Z. H. Zhang, Y. Sun and D. J. Kouri, Theor. Chim. Acta, $1987,72,237$.

35 Y. C. Zhang, J. Z. H. Zhang, D. J. Kouri, K. Haug, D. W Schwenke and D. G. Truhlar, Phys. Rev. Lett., 1988, 60, 2367.

36 D. J. Kouri, Y. Sun, R. C. Mowrey, J. Z. H. Zhang, D. G. Truhlar, K. Haug and D. W. Schwenke, in Mathematical Frontiers in Computational Chemical Physics, ed. D. G. Truhlar (Springer-Verlag, New York, 1988), p. 207.

37 M. J. Seaton, Philos. Trans. A, 1953, 245, 469.

38 D. A Micha, Ark. Fys., 1965, 30,411.

39 W. H. Miller, J. Chem. Phys., 1969, 50, 407

40 D. G. Truhlar, J. Abdallah Jr, and R. C. Smith, Adv. Chem. Phys., 1974, 25, 211.

41 D. W. Schwenke, D. G. Truhlar and D. J. Kouri, J. Chem. Phys., 1987, 86, 2772.

42 M. Baer and D. J. Kouri, J. Math. Phys., 1973, 14, 1637.

43 D. J. Kouri and F. S. Levin, Phys. Lett. B, 1974, 50, 421

44 W. Tobocman, Phys. Rev. C, 1974, 9, 2466.

45 D. J. Kouri and M. Baer, in The Theory of Chemical Reaction Dynamics, ed. D. C. Clary (Reidel, Dordrecht, 1986), p. 359.

46 I. P. Hamilton and J. C. Light, J. Chem. Phys., 1986, 84, 3096.

47 M. R. Hermann and W. H. Miller, Chem. Phys., 1986, 109, 163.

48 I. Percival and M. J. Seaton, Proc. Cambridge Philos. Soc., $1957,53,654$

49 A. M. Arthurs and A. Dalgarno, Proc. R. Soc. London, Ser. A, $1960,256,540$

50 E. H. S. Burhop, in Quantum Theory. I. Elements, ed. D. R. Bates (Academic, New York, 1961), p. 381.

51 N. F. Mott and H. S. W. Massey, The Theory of Atomic Collisions (Oxford University Press, London, 3rd edn, 1965), p. 349.

52 D. A. Micha, Ark. Fys., 1965, 30, 425

53 D. A. Micha, Ark. Fys., 1965, 30, 437

54 M. Karplus and K. T. Tang, Discuss. Faraday Soc., 1967, 44, 56.

55 K. T. Tang and M. Karplus, J. Chem. Phys., 1968, 49, 1676

56 W. H. Miller, J. Chem. Phys., 1968, 49, 2373.

57 R. D. Levine, Quantum Mechanics of Molecular Rate Processes (Oxford University Press, London, 1969), pp. 196ff
58 R. D. Levine, Israel J. Chem., 1970, 8, 13.

59 A. Gelb and R. J. Suplinskas, J. Chem. Phys., 1970, 53, 2249.

60 K. T. Tang and M. Karplus, Phys. Rev. A, 1971, 4, 1844.

61 K. T. Tang, J. Chem. Phys., 1973, 57, 1808.

62 R. B. Walker and R. E. Wyatt, Chem. Phys. Lett., 1972, 16, 52.

63 R. G. Gilbert, and T. F. George, Chem. Phys. Lett., 1973, 20, 187

64 A. M. Brodsky and V. G. Levich, J. Chem. Phys., 1973, 58, 3065.

65 R. B. Walker and R. E. Wyatt, J. Chem. Phys., 1974, 61, 4839

66 R. B. Walker and R. E. Wyatt, Mol. Phys., 1974, 28, 101.

67 B. H. Choi and K. T. Tang, J. Chem. Phys., 1974, 61, 2462.

68 B. H. Choi and K. T. Tang, J. Chem. Phys., 1974, 61, 5147.

69 K. T. Tang and B. H. Choi, J. Chem. Phys., 1975, 62, 3642

70 B. H. Choi and K. T. Tang, J. Chem. Phys., 1975, 63, 2854

71 P. A. Madden, Mol. Phys., 1975, 29, 381.

72 B. H. Choi and K. T. Tang, J. Chem. Phys., 1976, 65, 5161.

73 C. Zurht, F. Schneider and L. Zülicke, Chem. Phys. Lett., 1976, 43, 571 .

74 S. H. Suck, Phys. Rev. A, 1977, 15, 1893.

75 Y. Shan, B. H. Choi, R. T. Poe and K. T. Tang, Chem. Phys. Lett., 1978, 57, 379.

76 D. C. Clary and J. N. L. Connor, Chem. Phys. Lett., 1979, 66, 493.

77 Y. Y. Yung, B. H. Choi and K. T. Tang, J. Chem. Phys., 1980, 72,621

78 B. H. Choi, R. T. Poe, J. C. Sun and K. T. Tang, J. Chem. Phys., 1980, 73, 4381.

79 J. C. Sun, B. H. Choi, R. T. Poe and K. T. Tang, J. Chem. Phys., 1980, 73, 6095 .

80 J. C. Sun, B. H. Choi, R. T. Poe and K. T. Tang, Phys. Rev. Lett., 1980, 44, 211

81 D. C. Clary and J. N. L. Connor, Chem. Phys., 1980, 48, 175

82 D. C. Clary and J. N. L. Connor, Mol. Phys., 1980, 41, 689.

83 D. C. Clary and J. N. L. Connor, J. Chem. Phys., 1981, 74, 6991.

84 D. C. Clary and J. N. L. Connor, Mol. Phys., 1981, 43, 621.

85 D. C. Clary and J. N. L. Connor, J. Chem. Phys., 1981, 75, 3329.

86 S. H. Suck, Int. J. Quantum Chem., 1981, 19, 441

87 S. H. Suck, Chem. Phys. Lett., 1981, 77, 390

88 S. H. Suck and R. W. Emmons, Phys. Rev. A, 1981, 24, 129

89 S. H. Suck and R. W. Emmons, Chem. Phys. Lett., 1981, 79, 93.

90 S. H. Suck and R. W. Emmons, Phys. Rev. A, 1982, 25, 178

91 R. W. Emmons and S. H. Suck, Phys. Rev. A, 1983, 27, 1803.

92 S. H. Suck, Phys. Rev. A, 1983, 27, 187

93 L. M. Hubbard, S. H. Shi and W. H. Miller, J. Chem. Phys., 1983, 78, 2381.

94 G. C. Schatz, L. M. Hubbard, P. S. Dardi and W. H. Miller, J. Chem. Phys., 1984, 81, 231.

95 B. H. Choi, R. T. Poe and K. T. Tang, J. Chem. Phys., 1984, 81, 4979.

96 J. N. L. Connor and W. J. E. Southall, Chem. Phys. Lett., 1984, $108,527$.

97 S. H. Suck Salk, C. R. Klein and C. K. Lutrus, Chem. Phys. Lett., 1984, 110, 112.

98 K. T. Tang, in Theory of Chemical Reaction Dynamics, ed. M. Baer (CRC Press, Boca Raton, 1985), vol. 2, p. 125.

99 M. S. Bowers, B. H. Choi and R. T. Tang, Chem. Phys. Lett. 1985, 116, 239.

100 G. C. Schatz, J. Chem. Phys., 1985, 83, 5677.

101 D. C. Clary, J. N. L. Connor and W. J. E. Southall, J. Chem. Phys., 1986, 84, 2620.

102 J. N. L. Connor and W. J. E. Southall, Chem. Phys. Lett., 1986 123, 139.

103 G. C. Schatz, B. Amaee and J. N. L. Connor, Chem. Phys. Lett., 1986, $132,1$.

104 G. A. Natanson and G. C. Schatz, J. Chem. Phys., 1986, 85, 2038.

105 B. C. Garrett, D. G. Truhlar and G. C. Schatz, J. Am. Chem Soc., 1986, 108, 2876

106 G. C. Schatz, in The Theory of Chemical Reaction Dynamics, ed. D. C. Clary (Reidel, Dordrecht, 1986), p. 1.

107 J. N. L. Connor, ref. (106), p. 247.

108 G. C. Schatz, B. Amaee and J. N. L. Connor, Comput. Phys. Commun., 1987, 47, 45.

109 B. Amaee, J. N. L Connor, J. C. Whitehead, W. Jakubetz and G. C. Schatz, Faraday Discuss. Chem. Soc., 1987, 84, 387. 
110 G. C. Schatz, B. Amaee and J. N. L. Connor, J. Phys. Chem., $1989,92,3190$.

111 D. G. Truhlar and J. Abdallah, Phys. Rev. A, 1974, 9, 297.

112 S. K. Penny and G. R. Satchler, Nucl. Phys., 1964, 53, 145.

113 N. K. Glendenning, in Nuclear Spectroscopy and Reactions, Part D, ed. J. Cerny (Academic, New York, 1975), p. 319.

114 N. K. Glendenning, Lectures on Microscopic Theory of Nuclear Direct Reactions (Tata Institute of Fundamental Research, Bombay, 1978), chap. 13.

115 G. R. Stachler, Direct Nuclear Reactions (Oxford University Press, New York, 1983), sect. 3.6.

116 G. C. Schatz, Chem. Phys. Lett., 1988, 150, 92.

117 B. R. Johnson and N. W. Winter, J. Chem. Phys., 1977, 66, 4116.

118 B. R. Johnson and R. D. Levine, J. Chem. Phys., 1969, 50, 1902.

119 G. G. Balint-Kurti, in International Review of Science: Physical Chemistry, Series 2, ed. A. D. Buckingham and C. A. Coulson (Butterworths, London, 1975), vol. 1, p. 283.
120 M. J. Seaton, Proc. Phys. Soc. London, 1961, 77, 174.

121 J. H. Weare and E. Thiele, J. Chem. Phys., 1968, 48, 513.

122 R. D. Levine, J. Phys. B, 1969, $2,839$.

123 R. E. Roberts and J. Ross, J. Chem. Phys., 1970, 52, 6446.

124 D. G. Truhlar, Phys. Rev. A, 1971, 4, 1886.

125 B. C. Garrett, D. G. Truhlar, J. M. Bowman, A. F. Wagner, D. Robie, S. Arepalli, N. Presser and R. J. Gordon, J. Am. Chem. Soc., 1986, 108, 3515.

126 J. M. Bowman and A. F. Wagner, J. Chem. Phys., 1987, 86, 1967.

127 A. F. Wagner and J. M. Bowman, J. Chem. Phys., 1987, 86, 1976.

128 B. C. Garrett and D. G. Truhlar, Int. J. Quantum Chem., 1987, 31, 17.

129 D. C. Robie, S. Arepalli, N. Presser, T. Kitsopoulos and R. J. Gordon, Chem. Phys. Lett., 1987, 134, 579.

130 T. Joseph, D. G. Truhlar and B. C. Garrett, J. Chem. Phys., $1988,88,6982$.

Paper 9/04375F; Received 10th October, 1989 